\title{
A Dynamic Analysis of a Motor Vehicle Pollutant Emission Reduction Management Model Based on the SD-GM Approach
}

\author{
Shuwei Jia (iD \\ College of Information and Management Science, Henan Agricultural University, Zhengzhou 450002, China \\ Correspondence should be addressed to Shuwei Jia; shuweijia999666@163.com
}

Received 6 November 2017; Revised 29 June 2018; Accepted 12 July 2018; Published 1 August 2018

Academic Editor: Rodica Luca

Copyright (c) 2018 Shuwei Jia. This is an open access article distributed under the Creative Commons Attribution License, which permits unrestricted use, distribution, and reproduction in any medium, provided the original work is properly cited.

\begin{abstract}
The present study constructed a motor vehicle pollution charging management model by primarily reducing the trip volume of motor vehicles, introducing the charging mechanism, and employing integration of the system dynamics and grey model theory (SD-GM) from the perspective of the environment and society. To optimize the chosen parameters, the dynamic growth rate graphical function of the gross domestic product (GDP) was firstly generated based on the GM(1,1) prediction theory. In addition, verification was conducted in accordance with the degree of grey incidence. Secondly, the net migration rate was estimated based on the attraction degree of the city and the average net migration rate. The degree of PMx and NOx pollution was finally defined and endowed with different weights to define the degree of air pollution in accordance with the actual degree of air pollution in Beijing. In terms of model testing and verification, we conducted extreme condition tests and sensitivity tests and checked the residual error. Finally, this study analyzed and compared different policies, which indicate that the amount of motor vehicle trips (AMVT), the amount of PMx generation (APMG), the amount of NOx generation (ANOG), and the degree of air pollution (DAP) decreased by $31.01 \%, 26.52 \%, 21.29 \%$, and $12.50 \%$, respectively.
\end{abstract}

\section{Introduction}

With the continuous improvement of living standards and accelerated urbanization in China, transportation demands have rapidly increased. In addition, urban residents have gradually come to prefer automobiles as a means of transportation. The population of Chinese vehicles has rapidly increased since 2006, thereby boosting automobile quantities faster than the traffic capacity of urban roads. In addition, traffic jams and vehicle-induced exhaust gas pollution have become increasingly serious and not only influence traffic safety and the normal travel of residents but also result in air pollution, such as haze.

To solve these problems, scholars characterized exhaust gas emissions and air pollution to generate different methods of alleviating traffic jams and air pollution. In terms of energy conservation and emission reduction of vehicles, Liu et al. (2015) examined the passenger transport energy consumption and emissions in Beijing using scenario analyses and proposed measures to reduce vehicle emissions, thereby providing references for policy makers [1]. Xu et al. (2016) utilized provincial panel data from 2001 to 2012 and used the stochastic impacts by regression on population, affluence, and technology (STIRPAT) model to explore the driving forces of $\mathrm{PM}_{2.5}$ emissions in China [2]. The empirical results indicated that the inverted "U-shaped" impact of private vehicles may be due to the different roles of structural, scale, and technical effects at different stages. Leinert et al. (2013) studied the influence of automobile taxation policies on NOx emission, which provides policy references for research on vehicle emission reduction [3]. Cheng et al. (2017) used dynamic spatial panel models to analyze the driving factors of China's haze pollution based on 2001 to 2012 data covering $\mathrm{PM}_{2.5}$ concentrations in 285 cities [4]. The results identify a high proportion of haze pollution due to secondary industry, a coal-dominated energy structure, and increasing traffic intensity as key driving factors of urban $\mathrm{PM}_{2.5}$ pollution in China. In terms of the environmental perspective, Kaida (2015) examined the spillover effect of congestion charging on proenvironmental behavior [5]. Peñabaena-Niebles et al. (2015) researched the impact of transitions between signal timing plans in the social cost based on delays, fuel 
consumption, and air emissions [6]. Some scholars also examined various other problems such as traffic congestion $[7,8]$ and emissions [9-12], transportation networks [13], carbon taxation [14], and air quality [15-17]. In addition, certain scholars adopted economic means, such as the congestion pricing policy $[18,19]$, to characterize vehicle-induced traffic jams and exhaust gas emissions.

Nevertheless, scholars seldom employ system dynamics and dynamic simulation analyses for vehicle emission reduction research. Therefore, it is necessary to introduce the system dynamics approach because it emphasizes system behavior, structure, and causal feedback relationships. In addition, this paper also introduces the charging mechanism and increased vehicle trip costs by charging to reduce vehicle trips and PMx and NOx emissions. More importantly, it proposes a reduction management model for vehicle pollutant emissions on the basis of integrated system dynamics and the grey model theory (SD-GM approach), which can realize a long-term and dynamic simulation analysis.

\section{Methods}

2.1. System Dynamics Method. The system dynamics method, which is based on the system theory and computer simulation technology, characterizes the different behavior patterns of a complex system that are generated through time. In addition, the method analyzes the causal relationship between variables through the information feedback mechanism to determine the key problem variables that influence the system, thereby verifying the reasonability and stability of the constructed model through model tests and inspections. The effectiveness and practicability of the model are also validated based on the sensitivity analyses of parameters and the dynamic simulation of different policies to provide policy suggestions for solving problems.

2.1.1. Task Investigation and Objective Analysis. The continuous increase of exhaust emissions due to the continuous increase of motor vehicle ownership has resulted in the frequent presence of "haze" pollution in cities. Pollution degrees are generally more serious in metropolitan areas such as Beijing, Shanghai, and Guangzhou. According to research data, motor vehicle exhaust emission is one of the main sources of air pollution in China. As a result, a series of measures have been implemented to reduce the amount of motor vehicle trips (AMVT) to alleviate urban traffic jams and further constrain the degree of air pollution (DAP).

2.1.2. Stock-Flow Diagram and Causal Loop Diagram. The corresponding stock-flow diagram was generated based on the above analysis using the system dynamics software Vensim ${ }^{\circledR}$, as shown in Figure 1. Detailed descriptions were given in Appendix A. This stock-flow diagram presents two main loops that were derived based on the AMVT reduction and $\mathrm{PMx}(\mathrm{NOx})$ emission reduction analyses, as presented in Figure 2.

Loop 1 is a negative feedback loop. An increase in the initial NOx (PMx) emissions intensifies the degree of air pollution, thereby strengthening the air pollution control and increasing the cost of motor vehicle trips by the implementation of policies such as the air pollution charging fee (APCF). An increase in the cost of motor vehicle trips reduces the attraction degree of vehicle trips and the growth of vehicles, thereby reducing the growth rate of motor vehicles. In addition, a reduction in the growth rate of motor vehicles effectively restrains the increase of motor vehicles, reduces the AMVT, and finally reduces $\mathrm{NOx}(\mathrm{PMx})$ emissions. According to the loop, an initial increase in NOx (PMx) emissions reduces the final emissions values. Similarly, the analysis of loop 2 is presented in Figure 2.

2.2. Data Sources and Parameters Determination. The data source patterns were roughly divided into three kinds: analysis of the statistics, existing literature, and SD-GM approach.

2.2.1. Data of Official Website $\left(M_{1}\right)$. The use of a reference data model and the presence of strong data stability can be used to calculate the arithmetic mean value, among other things, based on historical statistical data and materials such as Statistical Yearbook of All Provinces and Cities, Statistical Yearbook of China, and China Automotive Industry Yearbook.

(1) According to Table 1, the initial amount of motor vehicles, initial value of population, and gross domestic product (GDP) gross are, respectively, listed as 4.019 million vehicles, 18.6 million persons, and 1.2153 trillion yuan.

(2) Initial value of amount of NOx generation (ANOG) $\approx 0.02 \times 401.9 \times 10^{4}=80,380$ tons; initial value of amount of $\mathrm{PMx}$ generation $(\mathrm{APMG}) \approx 0.04 \times 401.9 \times 10^{4}=160,760$ tons.

(3) The average of net migration rate.

The net migration rate is defined as net migration rate $=$ Mechanical increase / Average population of this region $\times 100 \%$, which was calculated based on Table 2: Net migration rate $_{2009}=112,163 / 1,860 \times 10^{4}=0.006030269 \approx 6.03 \%$. Similarly, the net migration rates for the years 2010 to 2014 were calculated as follows: net migration rate $2010=5.56 \%$; net migration rate $_{2011}=6.41 \%$; net migration rate $_{2012}=5.17 \%$; net migration rate $_{2013}=5.19 \%$; and net migration rate $_{2014}=$ $3.47 \%$. The preceding net migration rates were averaged as follows: net migration rate mean value $=5.31 \%$ o $=0.00531$.

2.2.2. Existing Literature $\left(M_{2}\right)$. For some of the special model parameters, refer to the researched data, such as for the contribution rate of $\mathrm{NOx}(\mathrm{PMx})$ of the vehicle, individual vehicle annual NOx (PMx) emissions, dissipation and control rate of $\mathrm{NOx}(\mathrm{PMx})$, and scrap rate. According to Yang et al. [20] and Zhu [21], (1) Per vehicle annual NOx emissions = $0.02 \mathrm{t} /$ year/vehicle; Per vehicle annual of PMx emissions = 0.04t/year/vehicle; (2) Contribution rate of NOx from the vehicle $=0.5$; Contribution rate of $\mathrm{PMx}$ from the vehicle $=$ 0.6; (3) Dissipation rate of $\mathrm{NOx}=0.2$; dissipation rate of $\mathrm{PMx}$ $=0.4$; (4) Scrap rate $=0.067$; (5) Ratio of motor vehicle trips $\approx 0.55$.

2.2.3. Indirect Data Based on SD-GM Approach $\left(M_{3}\right)$. The system dynamics and grey model theory refers to the approach integrating system dynamics and grey model theory. Incomplete data information or data stability poorly 


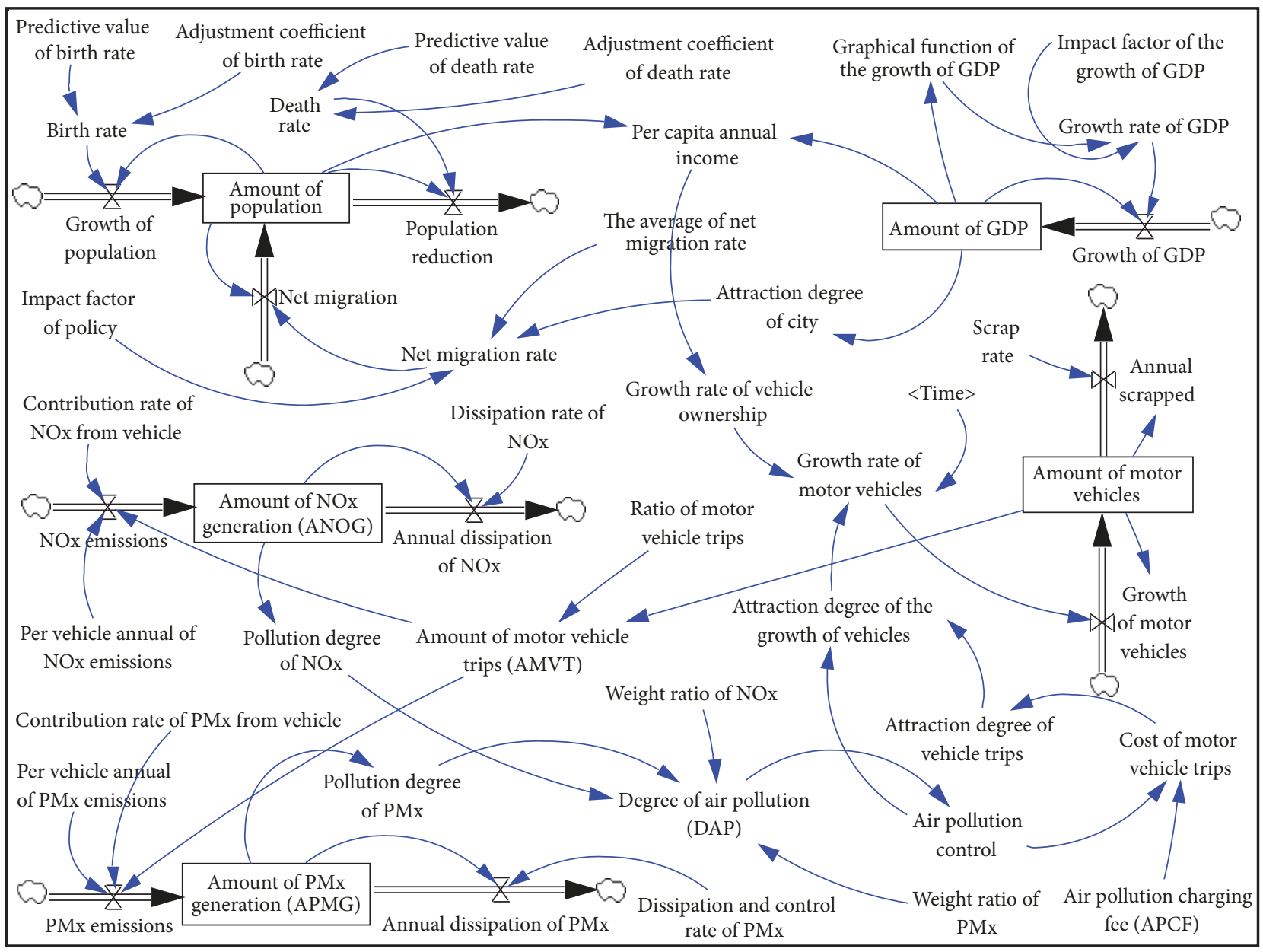

FIGURE 1: Stock-flow diagram of the motor vehicle pollution charging management model.

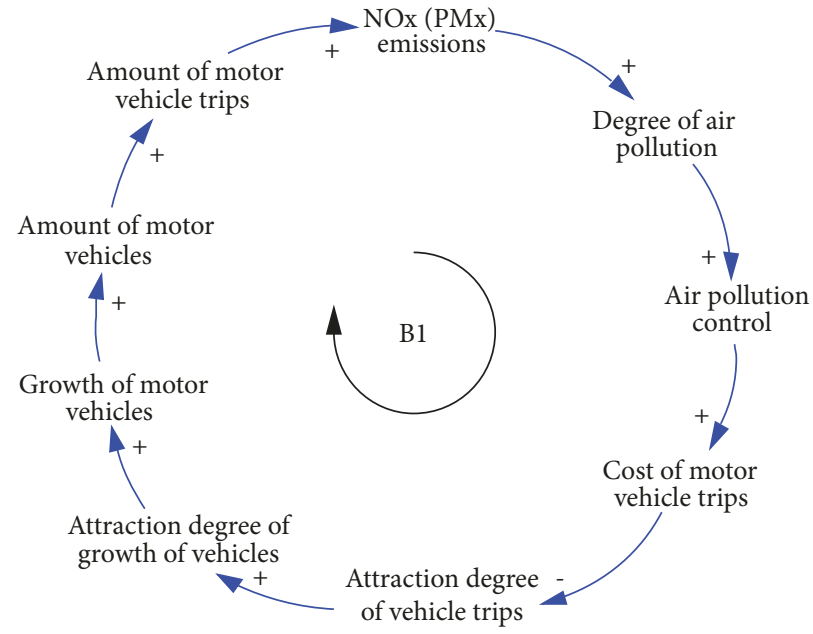

(a)

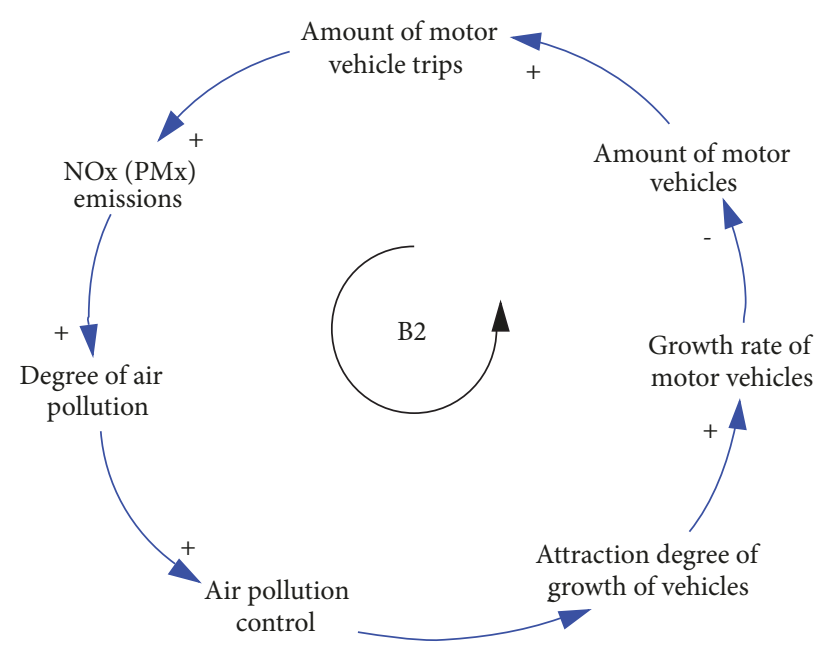

(b)

FIgURE 2: Major loops. (a) Negative feedback loop of NOx (PMx) emissions. (b) Negative feedback loop of AMVT. 
TABLE 1: Historical values of the main status variables (data is from 2010-2015 Statistical Yearbook of Beijing).

\begin{tabular}{|c|c|c|c|c|c|c|}
\hline Time & 2009 & 2010 & 2011 & 2012 & 2013 & 2014 \\
\hline $\begin{array}{l}\text { Amount of motor vehicles } \\
\text { (10,000 vehicles) }\end{array}$ & 401.9 & 480.9 & 498.3 & 520.0 & 543.7 & 559.1 \\
\hline $\begin{array}{l}\text { Amount of population } \\
(10,000 \text { persons })\end{array}$ & $1,860.0$ & $1,961.9$ & $2,018.6$ & $2,069.3$ & $2,114.8$ & $2,151.6$ \\
\hline $\begin{array}{l}\text { GDP gross } \\
\text { (100 million yuan) }\end{array}$ & $12,153.0$ & $14,113.6$ & $16,251.9$ & $17,879.4$ & $19,800.8$ & $21,330.8$ \\
\hline
\end{tabular}

TABLE 2: Historical values of main correlated variables. Unit: person.

\begin{tabular}{lcccccc}
\hline Time & $\mathbf{2 0 0 9}$ & $\mathbf{2 0 1 0}$ & $\mathbf{2 0 1 1}$ & $\mathbf{2 0 1 2}$ & $\mathbf{2 0 1 3}$ & $\mathbf{2 0 1 4}$ \\
\hline Mechanical increase & 112,163 & 109,091 & 129,313 & 107,072 & 109,656 & 74,654 \\
Inflows & 189,744 & 185,101 & 211,447 & 190,510 & 198,869 & 166,600 \\
Outflows & 77,581 & 76,010 & 82,134 & 83,438 & 89,213 & 91,946 \\
\hline
\end{tabular}

TABLE 3: Predictive value of birth rate and its average.

\begin{tabular}{lcccccc}
\hline Time & $\mathbf{2 0 1 5}$ & $\mathbf{2 0 1 6}$ & $\mathbf{2 0 1 7}$ & $\mathbf{2 0 1 8}$ & $\mathbf{2 0 1 9}$ & $\mathbf{2 0 2 0}$ \\
\hline $\begin{array}{l}\text { Predictive value } \\
\text { Average }\end{array}$ & $8.73 \% 0$ & $8.94 \% 0$ & $9.14 \%$ o & $9.35 \%$ o & $9.56 \%$ & $9.77 \%$ o \\
\hline
\end{tabular}

TABLE 4: Predictive value of death rate and its average.

\begin{tabular}{|c|c|c|c|c|c|c|}
\hline Time & 2015 & 2016 & 2017 & 2018 & 2019 & 2020 \\
\hline Predictive value & $4.73 \% 0$ & $4.83 \% \mathrm{o}$ & $4.64 \%$ & $5.04 \%$ & $5.15 \% 0$ & $\overline{5.25 \% \mathrm{o}}$ \\
\hline Average & \multicolumn{6}{|c|}{$4.94 \%$ o } \\
\hline
\end{tabular}

generated major errors in the mean-based forecast and estimation, which failed to meet the laws of change and data information development. The data was first processed using theoretical methods such as regression analysis and grey prediction. Valuable implicit rules were then generated in accordance with the actual changes in the data trends. Finally, a nonlinear relationship between variables was characterized in accordance with the graphical function, logical function, etc. Three methods are given in the following.

(1) First Method. The aim of this method is to determine a reasonable value to meet the actual situation of Beijing in recent years. Statistical approaches (such as regression analysis) based on large sample data can be used because of the abundance of data on birth and death rates. The value was first predicted by regression analysis, after which the mean value was calculated. Finally, the value was slightly adjusted by combining the actual change trends of the variables to determine the birth rate and death rate.

Tables 3 and 4 present the predicted data that were obtained from the regression analysis on the historical birth rate and death rate values of the permanent resident population in Beijing. However, the implementation of a population policy, specifically the "two-child policy", generated an increase in the birth rate. And the death rate remained at about $5 \%$. These results were consistent with the current status of Beijing.
(2) Second Method. The goal of this method is to describe the dynamic trends between variables by using the graphical function. Especially, grey prediction model can improve the prediction accuracy by the use of accumulated generating operator and buffer operator. Predictions were first conducted using the GM $(1,1)$ model in the absence of an obvious relationship between the variables or in the presence of imperfect data information. Subsequently, graphical or logical functions were generated by combining the actual change rules of the variables. This method was used to determine the growth rate of the gross domestic product (GDP) and vehicle ownership growth rate. Taking the GDP growth rate in Beijing as an example, the detailed calculations are presented in the following.

Definition 1. Assume that the original sequence is

$$
X^{(0)}=\left(x^{(0)}(1), x^{(0)}(2), \ldots, x^{(0)}(n)\right) .
$$

$X^{(1)}$ is its accumulation generated sequence (1-AGO)

$$
X^{(1)}=\left(x^{(1)}(1), x^{(1)}(2), \ldots, x^{(1)}(n)\right) \text {, }
$$

wherein

$$
x^{(1)}(k)=\sum_{i=1}^{k} x^{(0)}(i), \quad k=1,2, \ldots, n
$$


such that

$$
\frac{d x^{(1)}}{d t}+a x^{(1)}=b .
$$

The preceding equation is the winterization equation of the grey GM $(1,1)$ prediction model [22].

If $x^{(0)}(k) \geq 0, k=1,2, \ldots, n$, then $\hat{a}=(a, b)^{T}$ is the parameter list and satisfies

$$
\hat{a}=(a, b)^{T}=\left(B^{T} B\right)^{-1} B^{T} Y,
$$

wherein,

$$
\begin{aligned}
& B=\left[\begin{array}{cc}
-\frac{x^{(1)}(1)+x^{(1)}(2)}{2} & 1 \\
-\frac{x^{(1)}(2)+x^{(1)}(3)}{2} & 1 \\
\vdots & \vdots \\
-\frac{x^{(1)}(n-1)+x^{(1)}(n)}{2} & 1
\end{array}\right], \\
& Y=\left[\begin{array}{l}
x^{(0)}(2) \\
x^{(0)}(3) \\
\vdots \\
x^{(0)}(n)
\end{array}\right] .
\end{aligned}
$$

(i) Time response formula of the solution of the winterization equation $d x^{(1)} / d t+a x^{(1)}=b$ is

$$
x^{(1)}(t)=\left(x^{(1)}(1)-\frac{b}{a}\right) e^{-a t}+\frac{b}{a} .
$$

(ii) Time response formula of the $\mathrm{GM}(1,1) \operatorname{model} x^{(0)}(k)+a$. $\left(x^{(1)}(k)+x^{(1)}(k-1)\right) / 2=b$ is

$$
\begin{aligned}
\hat{x}^{(1)}(k+1)=\left(x^{(0)}(1)-\frac{b}{a}\right) e^{-a k}+\frac{b}{a}, & \\
k & =1,2,3, \ldots, n .
\end{aligned}
$$

(iii) Predicted value model of the original model is

$$
\begin{aligned}
\hat{Y}(k+1) & =\hat{x}^{(0)}(k+1)=\hat{x}^{(1)}(k+1)-\hat{x}^{(1)}(k) \\
& =\left(1-e^{a}\right)\left(x^{(0)}(1)-\frac{b}{a}\right) e^{-a k} .
\end{aligned}
$$

The following definitions are provided in Liu et al. [23].
Definition 2. Assume that the images of zero starting point of these two sequences

$$
\begin{aligned}
& X_{i}=\left(x_{i}(1), x_{i}(2), \ldots, x_{i}(n)\right), \\
& X_{j}=\left(x_{j}(1), x_{j}(2), \ldots, x_{j}(n)\right)
\end{aligned}
$$

are

$$
\begin{aligned}
& X_{i}^{0}=\left(x_{i}^{0}(1), x_{i}^{0}(2), \ldots, x_{i}^{0}(n)\right), \\
& X_{j}^{0}=\left(x_{j}^{0}(1), x_{j}^{0}(2), \ldots, x_{j}^{0}(n)\right),
\end{aligned}
$$

such that

$$
\xi_{i j}=\frac{1+\left|s_{i}\right|+\left|s_{j}\right|}{1+\left|s_{i}\right|+\left|s_{j}\right|+\left|s_{i}-s_{j}\right|} .
$$

The presented equation is the absolute degree of grey incidence (GAID) of $X_{i}$ and $X_{j}$. Assume that $X_{i}$ and $X_{j}$ are sequences of the same length with nonzero initial values, $X_{i}^{\prime}$ and $X_{j}^{\prime}$ are the initial images of $X_{i}$ and $X_{j}$, respectively, $X^{\prime^{0}}{ }_{i}$ and $X_{j}^{\prime 0}$ are the images of the zero starting point of sequences $X_{i}^{\prime}$ and $X_{j}^{\prime}$, respectively, and the GAID of $X_{i}^{\prime}$ and $X_{j}^{\prime}$ is called the relative degree of grey incidence (GRID) of $X_{i}$ and $X_{j}$. Based on these definitions, the following equation is then defined:

$$
r_{i j}=\frac{1+\left|s^{\prime}{ }_{i}\right|+\left|s^{\prime}{ }_{j}\right|}{1+\left|s^{\prime}{ }_{i}\right|+\left|s^{\prime}{ }_{j}\right|+\left|s^{\prime}{ }_{i}-s^{\prime}{ }_{j}\right|},
$$

such that

$$
\varepsilon_{i j}=\theta \xi_{i j}+(1-\theta) r_{i j}
$$

is defined as the synthetic degree of grey incidence (GSID) of $X_{i}$ and $X_{j}$, wherein $\theta \in[0,1]$.

Definition 3. Assume that $X^{(0)}$ is the original sequence, $\stackrel{(}{X}^{(0)}$ is its simulative sequence, and $\varepsilon$ is the degree of grey incidence between $X^{(0)}$ and $\hat{X}^{(0)}$. In the case of $\varepsilon>\varepsilon_{0}$ for the given $\varepsilon_{0}>0$, this model is defined as the qualified verification of the degree of grey incidence. See Table 5 for the accuracy test grade.

The requirement of this model for correlation $\varepsilon$ is "the bigger the better".

Step 1 (data processing). First, write the original data as the form of sequence

$$
\begin{aligned}
X^{(0)} & =\left(x^{(0)}(1), x^{(0)}(2), \ldots, x^{(0)}(10)\right) \\
& =(8117.8,9846.8,11115.0,12153.0,14113.6,16251.9,17879.4,19800.8,21330.8,23014.6) .
\end{aligned}
$$


Second, introduce the second-order average weakening operator $D^{2}$ as

$$
X^{(0)} D^{2}=\left(x^{(0)}(1) d^{2}, x^{(0)}(2) d^{2}, \ldots, x^{(0)}(10) d^{2}\right),
$$

wherein

$$
\begin{aligned}
& \left.+\ldots+x^{(0)}(10) d\right] \\
& x^{(0)}(k) d=\frac{1}{10-k+1}\left[x^{(0)}(k)+x^{(0)}(k+1)+\ldots\right. \\
& \left.\quad+x^{(0)}(10)\right], \quad k=1,2,3, \ldots, 10 .
\end{aligned}
$$

$x^{(0)}(k) d^{2}=\frac{1}{10-k+1}\left[x^{(0)}(k) d+x^{(0)}(k+1) d\right.$

$$
\begin{aligned}
X^{(0)} D^{2} & =(19174.2,19597.8,20026.6,20465,20910.5,21346.3,21769,22189.8,22593.7,23014.6) \triangleq X \\
& =(x(1), x(2), x(3), \ldots, x(10)) .
\end{aligned}
$$

Step 2. Calculate the 1-AGO sequence of sequence $X$, and obtain sequence $X^{(1)}$ :

$$
\begin{aligned}
X^{(1)} & =\left(x^{(1)}(1), x^{(1)}(2), x^{(1)}(3), \ldots, x^{(1)}(10)\right) \\
& =(19174.2,38772,58798.6,79263.6,100174.1,121520.4,143289.4,165479.2,188072.9,211087.5) .
\end{aligned}
$$

Step 3. Calculate its simulative sequence based on the grey GM $(1,1)$ prediction model.

According to Definition 1, the grey GM $(1,1)$ prediction model is used to obtain the time response formula as follows:

$$
\begin{aligned}
\stackrel{\wedge}{X} & =(\hat{x}(1), \hat{x}(2), \ldots, \hat{x}(10)) \\
& =(19174.2,19653.6,20051.57,20457.6,20871.85,21294.48,21725.68,22165.61,22614.44,23072.36)
\end{aligned}
$$

$$
\begin{aligned}
\hat{x}^{(1)}(k+1) & =972818.2 e^{0.02 k}-953644, \\
\hat{Y} & (k+1)=\hat{x}^{(0)}(k+1)=\hat{x}^{(1)}(k+1)-\hat{x}^{(1)}(k) .
\end{aligned}
$$

The simulative sequence can then be calculated as
Step 4 (accuracy test). According to Steps 1 and 3, the original sequence and its simulative sequence were, respectively, calculated as follows:

$$
X=\left[\begin{array}{c}
x(1) \\
x(2) \\
x(3) \\
\vdots \\
x(10)
\end{array}\right]=\left[\begin{array}{c}
19174.2 \\
19597.8 \\
20026.6 \\
20465.0 \\
20910.5 \\
21346.3 \\
21769.0 \\
22189.8 \\
22593.7 \\
23014.6
\end{array}\right],
$$

$$
\hat{X}=\left[\begin{array}{c}
\hat{x}(1) \\
\hat{x}(2) \\
\hat{x}(3) \\
\vdots \\
\hat{x}(10)
\end{array}\right]=\left[\begin{array}{c}
19174.2 \\
19653.60 \\
20051.57 \\
20457.60 \\
20871.85 \\
21294.48 \\
21725.68 \\
22165.61 \\
22614.44 \\
23072.36
\end{array}\right]
$$


TABLE 5: Reference list of accuracy test grade.

\begin{tabular}{lcccc}
\hline Accuracy grade & Grade 1 & Grade 2 & Grade 3 & Grade 4 \\
\hline Degree of grey incidence $\varepsilon_{0}$ & 0.90 & 0.80 & 0.70 & 0.60 \\
\hline
\end{tabular}

TABLE 6: Amount of GDP and its growth rate.

\begin{tabular}{lccccc}
\hline Time & Amount of GDP $(\mathbf{t})$ & Growth rate & Time & Amount of GDP (t) & Growth rate \\
\hline 2005 & $6.9695 \mathrm{e}+011$ & --- & 2013 & $1.98008 \mathrm{e}+012$ & 0.1075 \\
2006 & $8.1178 \mathrm{e}+011$ & 0.1648 & 2014 & $2.13308 \mathrm{e}+012$ & 0.0773 \\
2007 & $9.8468 \mathrm{e}+011$ & 0.2130 & 2015 & $2.30146 \mathrm{e}+012$ & 0.0789 \\
2008 & $1.1115 \mathrm{e}+012$ & 0.1288 & 2016 & $2.353956 \mathrm{e}+012$ & 0.02281 \\
2009 & $1.2153 \mathrm{e}+012$ & 0.0934 & 2017 & $2.401622 \mathrm{e}+012$ & 0.02030 \\
2010 & $1.41136 \mathrm{e}+012$ & 0.1613 & 2018 & $2.450253 \mathrm{e}+012$ & 0.02025 \\
2011 & $1.62519 \mathrm{e}+012$ & 0.1515 & 2019 & $2.499868 \mathrm{e}+012$ & 0.02024 \\
2012 & $1.78794 \mathrm{e}+012$ & 0.1001 & 2020 & $2.550488 \mathrm{e}+012$ & 0.020249 \\
\hline
\end{tabular}

$$
=17425.3
$$

$$
\begin{aligned}
|\hat{s}| & =\left|\sum_{k=2}^{9}[\hat{x}(k)-\hat{x}(1)]+\frac{1}{2}[\hat{x}(10)-\hat{x}(1)]\right| \\
& =17390.31,
\end{aligned}
$$

$$
\begin{aligned}
|\hat{s}-s| & =\mid \sum_{k=2}^{9}[x(k)-x(1)-(\hat{x}(k)-\hat{x}(1))] \\
& +\frac{1}{2}[x(10)-x(1)-(\hat{x}(10)-\hat{x}(1))] \mid=34.99,
\end{aligned}
$$

such that

$$
\xi=\frac{1+|s|+|\hat{s}|}{1+|s|+|\hat{s}|+|\hat{s}-s|} \approx 0.9990
$$

Similarly, $r=0.9993$, when $\theta=0.5, \exists \varepsilon_{0}=0.9$, thereby defining

$$
\varepsilon=\theta \xi+(1-\theta) r=0.9991>0.9=\varepsilon_{0} .
$$

Therefore, this model is defined as the qualified verification of the degree of grey incidence.

Step 5 (predict future data). According to

$$
\begin{aligned}
& \hat{x}^{(1)}(k+1)=972818.2 e^{0.02 k}-953644, \\
& \hat{x}^{(0)}(k+1)=\hat{x}^{(1)}(k+1)-\hat{x}^{(1)}(k),
\end{aligned}
$$

a prediction of the next five steps was calculated as follows:

$$
\hat{X}=\left[\begin{array}{ll}
\hat{x}^{(0)} & (11) \\
\hat{x}^{(0)} & (12) \\
\hat{x}^{(0)} & (13) \\
\hat{x}^{(0)} & (14) \\
\hat{x}^{(0)} & (15)
\end{array}\right]=\left[\begin{array}{l}
23539.56 \\
24016.22 \\
24502.53 \\
24998.68 \\
25504.88
\end{array}\right] .
$$

Step 6 (establish the graphical function). The GDP gross and its growth rate (2005-2020) were calculated using the above steps. See Table 6 for specific results.

Therefore, one may establish the graphical function of the growth of GDP:

Graphical function of the growth of GDP $=$ WITH LOOKUP (Amount of GDP, $([(8 \mathrm{e}+011,0)-(3 \mathrm{e}+012,0.3)]$, $(8.1178 \mathrm{e}+011,0.1648), \quad(9.8468 \mathrm{e}+011,0.213), \quad(1.1115 \mathrm{e}+012$, $0.1288), \quad(1.2153 \mathrm{e}+012, \quad 0.0934), \quad(1.41136 \mathrm{e}+012,0.1613)$, $(1.62519 \mathrm{e}+012,0.1515),(1.78794 \mathrm{e}+012,0.1001), \quad(1.98008 \mathrm{e}+$ $012,0.1075),(2.13308 \mathrm{e}+012,0.0773),(2.30146 \mathrm{e}+012,0.0789)$, $(2.35396 \mathrm{e}+012,0.02281),(2.40162 \mathrm{e}+012,0.0203),(2.45025 \mathrm{e}+$ $012, \quad 0.02025), \quad(2.49987 \mathrm{e}+012,0.02024), \quad(2.55049 \mathrm{e}+012$, $0.020249))$ ).

Similarly, one may establish the Graphical function about the growth rate of vehicle ownership. See Appendix B for specific results.

(3) Third Method. The purpose of this method is to determine some variables with nonlinear characteristics because they are difficult to define directly, such as degree of air pollution and air pollution control. In the actual situation, estimations were conducted by utilizing data from the official website $\left(\mathrm{M}_{1}\right)$ and the first two prediction methods. Main basis: Slightly adjust the change trend of the variables to meet the actual change rules that have been observed in Beijing in recent years. As a result, several variables have been 
TABLE 7: Estimated values of pollution degree of NOx and PMx in Beijing.

\begin{tabular}{lcccc}
\hline Time & Amount of motor vehicles (vehicle) & ANOG (t) & APMG (t) & Actual pollution degree \\
\hline 2014 & $5.591 \mathrm{e}+006$ & $1.1182 \mathrm{e}+005$ & $2.2364 \mathrm{e}+005$ & Serious pollution \\
2013 & $5.437 \mathrm{e}+006$ & $1.0874 \mathrm{e}+005$ & $2.1748 \mathrm{e}+005$ & Serious pollution \\
2012 & $5.200 \mathrm{e}+006$ & $1.0400 \mathrm{e}+005$ & $2.0800 \mathrm{e}+005$ & Moderate pollution \\
2011 & $4.983 \mathrm{e}+006$ & $9.966 \mathrm{e}+004$ & $1.9932 \mathrm{e}+005$ & Moderate pollution \\
2010 & $4.809 \mathrm{e}+006$ & $9.618 \mathrm{e}+004$ & $1.9236 \mathrm{e}+005$ & Moderate pollution \\
2009 & $4.019 \mathrm{e}+006$ & $8.038 \mathrm{e}+004$ & $1.6076 \mathrm{e}+005$ & Mild pollution \\
2008 & $3.504 \mathrm{e}+006$ & $7.008 \mathrm{e}+004$ & $1.4016 \mathrm{e}+005$ & Mild pollution \\
2007 & $3.072 \mathrm{e}+006$ & $6.144 \mathrm{e}+004$ & $1.2288 \mathrm{e}+005$ & Mild pollution \\
2006 & $2.754 \mathrm{e}+006$ & $5.508 \mathrm{e}+004$ & $1.1016 \mathrm{e}+005$ & Mild pollution \\
\hline
\end{tabular}

confirmed, including the attraction degree of the city, net migration rate, degree of air pollution, air pollution control, attraction degree of vehicle trips, attraction degree of growth of the vehicles, and growth rate of motor vehicles. The present study characterized the degree of air pollution as an example.

(a) Estimation of Degree of Air Pollution. The present study estimated the degree of air pollution mainly based on the amount of NOx generation (ANOG) and amount of PMx generation (APMG), in accordance with historical data in Statistical Yearbook of Beijing from 2006 to 2014. In addition, the methods were also combined to estimate the ANOG and APMG. See Table 7 for detailed results.

According to the actual situation of air pollution caused by motor vehicle exhaust emission in Beijing, serious pollution was observed from 2013 to 2014, moderate pollution was generated between 2010 and 2012, and mild pollution occurred before 2009. Therefore, this paper defines the degree of air pollution caused by ANOG as follows:

(I) The degree of air pollution exhibited a value range that is defined as $(0,1)$, wherein a value of 0.8 and above indicates serious pollution, a value lower than 0.8 but higher than 0.5 means moderate pollution, and a value lower than 0.5 means mild pollution.

(II) From 2013 to 2014, Beijing exhibited a very serious degree of air pollution, such that the estimated value of NOx pollution was characterized between 0.8 and 1 at a corresponding ANOG of 108,740 t to 111,820 t. From 2010 to 2012, the degree of air pollution was moderate, such that the estimated value of pollution NOx was within the interval of $(0.5,0.8)$ at a corresponding ANOG of $96,180 \mathrm{t}$ to $104,000 \mathrm{t}$. From 2006 to 2009, the pollution degree was mild, such that the estimated value of NOx pollution was lower than 0.5 .

According to the provisions above, establish the logical function of pollution degree of NOx:

Pollution degree of NOx = IF THEN ELSE (Amount of NOx generation $>=1.1182 \mathrm{e}+005,0.9$, IF THEN ELSE (Amount of NOx generation $>=1.0874 \mathrm{e}+005,0.8$, IF THEN ELSE (Amount of NOx generation $>=1.0400 \mathrm{e}+005,0.7$, IF THEN ELSE (Amount of NOx generation $>=9.966 \mathrm{e}+004,0.6$, IF THEN ELSE (Amount of NOx generation $>=9.618 \mathrm{e}+004,0.5$, IF THEN ELSE (Amount of NOx generation $>=8.038 \mathrm{e}+004$, 0.3, IF THEN ELSE (Amount of NOx generation $>=$ $7.008 \mathrm{e}+004,0.25$, IF THEN ELSE (Amount of NOx generation $>=6.144 \mathrm{e}+004,0.2$, IF THEN ELSE (Amount of NOx generation $>=5.508 \mathrm{e}+004,0.15,0.1))))$ )) )) )

In the same way, one can establish the logical function of pollution degree of $\mathrm{PMx}$ :

Pollution degree of PMx = IF THEN ELSE (Amount of PMx generation $>=2.2364 \mathrm{e}+005,0.9$, IF THEN ELSE (Amount of PMx generation $>=2.1748 \mathrm{e}+005,0.8$, IF THEN ELSE (Amount of PMx generation $>=2.0800 \mathrm{e}+005,0.7$, IF THEN ELSE (Amount of PMx generation $>=1.9932 \mathrm{e}+005$, 0.6, IF THEN ELSE (Amount of PMx generation $>=$ $1.9236 \mathrm{e}+005,0.5$, IF THEN ELSE (Amount of PMx generation $>=1.6076 \mathrm{e}+005,0.3$, IF THEN ELSE (Amount of PMx generation $>=1.4016 \mathrm{e}+005,0.25$, IF THEN ELSE (Amount of PMx generation $>=1.2288 \mathrm{e}+005,0.2$, IF THEN ELSE (Amount of PMx generation $>=1.1016 \mathrm{e}+005,0.15,0.1$ ()$))))))$ )

Therefore,

$$
\begin{aligned}
& \text { Degree of air pollution } \\
& =\beta * \text { pollution degree of } N O x+\gamma \\
& \quad * \text { pollution degree of } P M x,
\end{aligned}
$$

wherein $\beta$ refers to the weight ratio of NOx, $\gamma$ refers to weight ratio of $\mathrm{PMx}$, and $\beta+\gamma=1$.

(b) Estimation of Net Migration Rate. According to Jia et al. (2017), the attraction degree in Beijing was calculated to be about 0.7056 [24].

According to Table 2, the permanent resident population in Beijing exhibited a mechanical increase from 2009 to 2014, respectively, 112,163, 109,091, 129,313, 107,072, 109,656, and 74,654 persons. Therefore, the net migration rates were, respectively, calculated as $6.03 \%, 5.56 \%, 6.41 \%, 5.17 \%, 5.19 \%$, and $3.47 \%$. A continuously decreasing trend was observed due to registered residence migration and settlement policies in Beijing. In addition, the net migration rate (mean value) of $5.31 \%$ must be adjusted given that it is obviously higher than $3.47 \%$ and is inconsistent with the actual conditions in Beijing. Therefore, the present study set the following conditions:

$$
\begin{aligned}
& \text { Net migration rate } \\
& \quad=\text { net } \text { migration }_{\text {rate }} \text { mean value }
\end{aligned}
$$




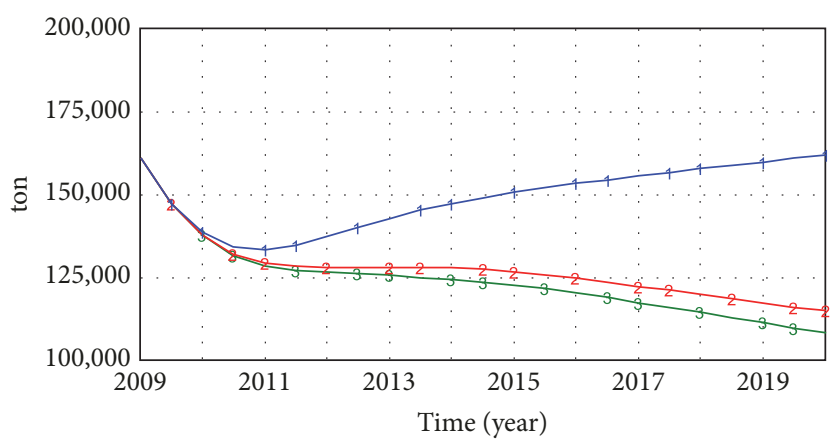

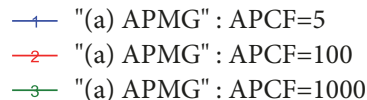

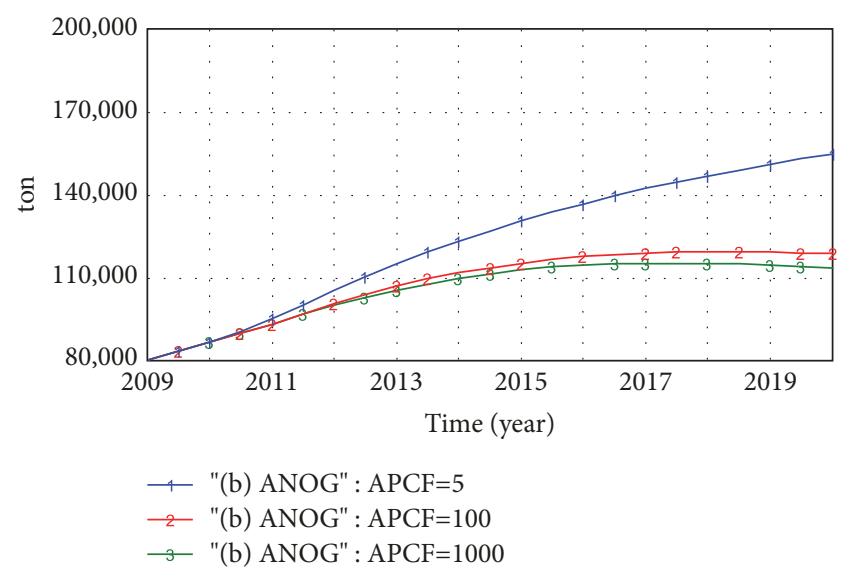

(b) ANOG

(a) APMG

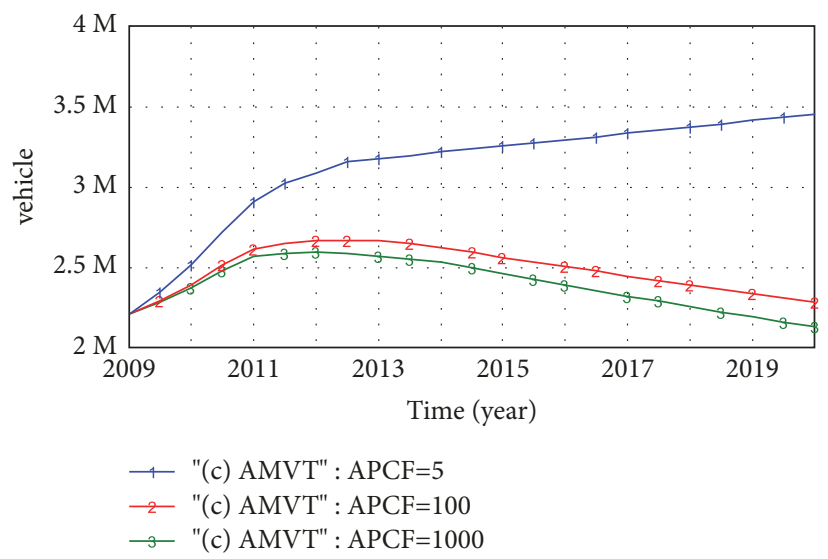

(c) AMVT

Figure 3: Extreme condition test. (a) APMG. (b) ANOG. (c) AMVT.

$$
\times \text { attraction degree of } c i t y^{\alpha} \text {, }
$$

where $\alpha$ refers to the impact factor of policy. Based on this calculation, $\alpha=1.5$ generates calculations that are close to the actual value. See the appendixes for descriptions of the other variables and main equations.

\section{Simulation and Result Analysis}

\subsection{Model Test}

3.1.1. Extreme Condition Test. The extreme condition test mainly aims to inspect the stability, applicability in extreme conditions, and accuracy of the equations in the test model to represent the change trends of the realistic system and the intentions of the decision maker.

According to Figure 3(a), the APMG exhibited a continuous decrease following an increase in the APCF. In particular, the minimum value of APMG was obtained when the APCF was at the limit value (1000 yuan/day-vehicle). In addition, when APCF was equal to 5, the maximum APMG value was obtained, which is consistent with the actual laws, thereby confirming the stability of the model in extreme conditions.
A deeper analysis indicated a larger interval between curves 1 and 2 and a shorter interval between curves 2 and curve 3, thereby indicating that the APCF did not exceed 100 yuan/day.vehicle.

The change rules presented in Figures 3(b) and 3(c) were similar to those in Figure 3(a).

3.1.2. Sensitivity Test. The model behaviors exhibited different and sensitive results at different parameter values. Specifically, the behavior model changed following an appropriate change of parameter. In addition, the policies generated through the model analysis changed following a change in parameters.

According to Figure 4(a), with time, all the curves first rose and then slowly descended. Specifically, in the early period of policy implementation (before 2014), the effect was not obvious because part-time drivers may not have had a deep understanding of the purpose of the implementation and the significance of the APCF policy, thereby resulting in a continuous increase in AMVT due to sharp increase in motor vehicle ownership. The AMVT growth rate was more effectively controlled following a longer period due to continuous policy implementation and fulfilment. After 2016, the growth rate continuously decreased, thereby allowing 


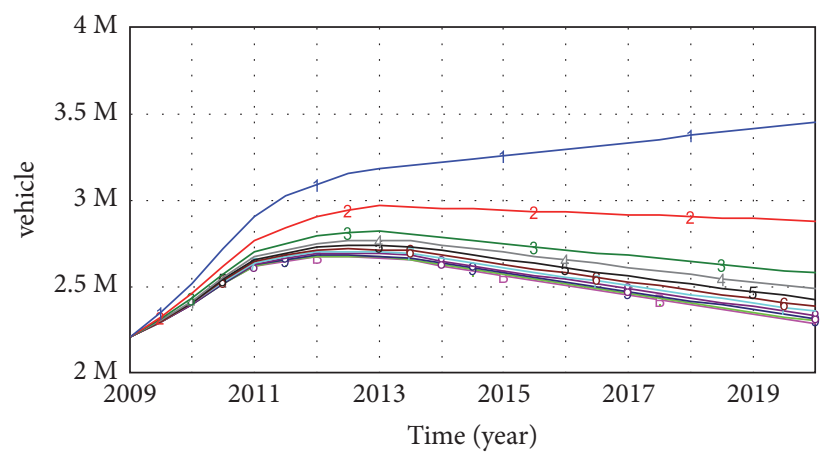

$$
\begin{aligned}
& 1 \text { "(a) AMVT" : } \mathrm{APCF}=5 \\
& -2 \text { "(a) AMVT" : } \mathrm{APCF}=10 \\
& \longrightarrow \text { "(a) AMVT" : } \mathrm{APCF}=20 \\
& \neg \text { "(a) AMVT" : } \mathrm{APCF}=30 \\
& \rightarrow \text { "(a) AMVT" : } \mathrm{APCF}=40 \\
& \rightarrow \text { "(a) AMVT" : } \mathrm{APCF}=50 \\
& \rightarrow \text { "(a) AMVT" : APCF }=60 \\
& \rightarrow \text { "(a) AMVT" : } \mathrm{APCF}=70 \\
& \rightarrow \text { "(a) AMVT" : APCF }=80 \\
& \because \quad \text { "(a) AMVT" : } \mathrm{APCF}=90 \\
& \rightarrow \text { - "(a) AMVT" : APCF }=100
\end{aligned}
$$

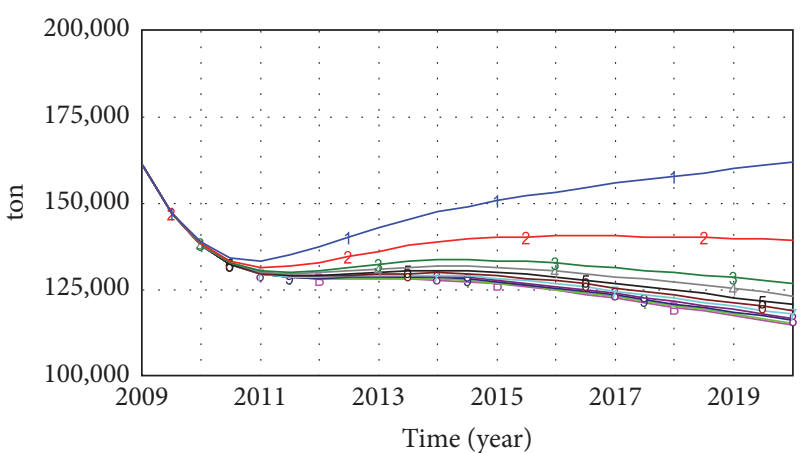

ч "(b) $\mathrm{APMG}$ " : $\mathrm{APCF}=5$

2 "(b) $A P M G ": A P C F=10$

ـ "(b) $A P M G ": A P C F=20$

-4 "(b) $\mathrm{APMG}^{\prime}: \mathrm{APCF}=30$

$\rightarrow$ "(b) $A P M G ": A P C F=40$

$\rightarrow$ "(b) $A P M G ": A P C F=50$

7 "(b) $\mathrm{APMG} ": \mathrm{APCF}=60$

-8 "(b) $\mathrm{APMG} ": \mathrm{APCF}=70$

$\multimap$ "(b) APMG" : APCF $=80$

- "(b) $\mathrm{APMG}$ " : $\mathrm{APCF}=90$

$\rightarrow$ "(b) APMG" : APCF $=100$

(a) AMVT

(b) APMG
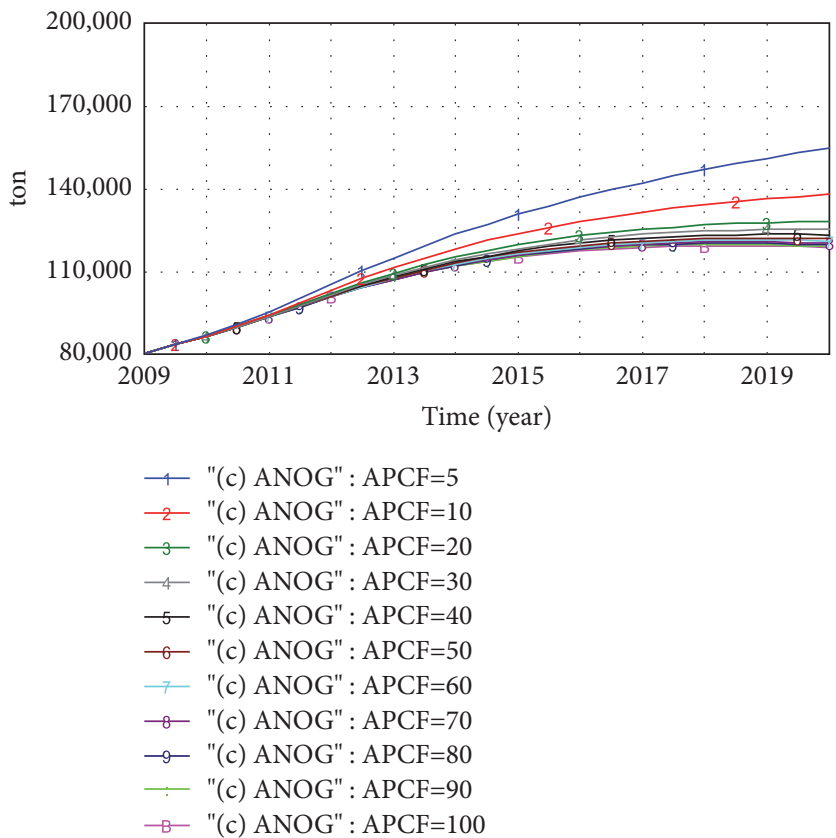

(c) ANOG

Figure 4: Sensitivity test. (a) AMVT. (b) APMG. (c) ANOG.

the APCF policy to exhibit good effects based on long-term practice, improvement, and fulfilment.

Following further analysis, the AMVT exhibited a marginal decreasing effect following an increase in APCF from curve 1 to curve 6 , especially in curves 3-6, which indicates that a larger APCF is not always better. The analysis results are presented in Figures 4(b) and 4(c).

In conclusion, the APCF value range was observed within the interval of $[30,50]$ based on the above analysis from the perspective of AMVT reduction (alleviate traffic jam) as well as APMG and ANOG emission reduction. Table 8 presents the detailed analysis results.

3.2. Analysis of Results. The AMVT exhibited a continuous decrease following an increase in APCF, which indicates the ability of this policy to restrict increases in AMVT. Specifically, obvious changes were in the intervals of $[5,10]$ and $[10,20]$, wherein the AMVT exhibited a decrease of $16.6649 \%$ 
and $10.5055 \%$, respectively. The AMVT exhibited a decrease of $3.5103 \%, 2.4912 \%$, and $1.6793 \%$ in the intervals of $[20,30]$, $[30,40]$, and $[40,50]$, respectively. However, minimal changes were observed in the interval of 50 yuan/day.vehicle above. In addition, the APMG exhibited a decrease of $13.9677 \%$, $8.9137 \%, 2.8538 \%, 2.0987 \%$, and $1.4128 \%$, respectively, in the above intervals and exhibited very minimal changes in the interval of 50 above. The ANOG exhibited similar change rules.

Therefore, the interval $[30,50]$ is deemed a reasonable value range based on the analysis on the degree of effect of different APCFs on the AMVT, APMG, and ANOG.

In particular, the change trends of AMVT, APMG, and ANOG were generally consistent, as presented in Figure 6, specifically Figure 5(d). Figures 5(a)-5(c) exhibited obvious decreasing trend rates that were continuously weakened in the interval of $[30,50]$. In addition, the change was very limited as the APCF exceeded 50 yuan/day.vehicle.

Therefore, an effective APCF range of $[30,50]$ was chosen based on the development trends analysis of the change rates of the main variables.

3.3. Model Validation. Historical data (2009-2015) on the amount of motor vehicles and population in Beijing are presented in Table 9, wherein the conformance of their respective GSID was tested.

3.3.1. Qualified Verification of the Degree of Grey Incidence on the Population of Beijing. The original sequence and its simulation value sequence are, respectively, presented as follows:

$$
\begin{gathered}
X_{0}=\left[\begin{array}{c}
x_{0}(1) \\
x_{0}(2) \\
x_{0}(3) \\
\vdots \\
x_{0}(7)
\end{array}\right]=\left[\begin{array}{c}
1.8600 e+007 \\
1.9619 e+007 \\
2.0186 e+007 \\
2.0693 e+007 \\
2.1148 e+007 \\
2.1516 e+007 \\
2.1705 e+007
\end{array}\right], \\
X_{1}=\left[\begin{array}{c}
1.86000 e+007 \\
1.87390 e+007 \\
x_{1}(1) \\
x_{1}(3) \\
\vdots \\
x_{1}(7)
\end{array}\right]=\left[\begin{array}{c}
1.88790 e+007 \\
1.91621 e+007 \\
1.93053 e+007 \\
1.94495 e+007
\end{array}\right] .
\end{gathered}
$$

The following was derived based on their calculations:

$$
\left|s_{0}\right|=\left|\sum_{k=2}^{6} x_{0}^{0}(k)+\frac{1}{2} x_{0}^{0}(7)\right|=1.17145
$$

$$
\begin{aligned}
\left|s_{1}\right| & =\left|\sum_{k=2}^{6} x_{1}^{0}(k)+\frac{1}{2} x_{1}^{0}(7)\right|=0.25295 \\
\left|s_{0}-s_{1}\right| & =\left|\sum_{k=2}^{6}\left(x_{1}^{0}(k)-x_{0}^{0}(k)\right)+\frac{1}{2}\left(x_{1}^{0}(7)-x_{0}^{0}(7)\right)\right| \\
& =0.9185 .
\end{aligned}
$$

Therefore, we are able to obtain the value of the GAID:

$$
\begin{aligned}
\xi_{01} & =\frac{1+\left|s_{0}\right|+\left|s_{1}\right|}{1+\left|s_{0}\right|+\left|s_{1}\right|+\left|s_{0}-s_{1}\right|} \\
& =\frac{1+1.17145+0.25295}{1+1.17145+0.25295+0.9185} \approx 0.7275
\end{aligned}
$$

In a similar way,

$$
\begin{aligned}
\left|s_{0}^{\prime}\right| & =\left|\sum_{k=2}^{6} x_{0}^{\prime 0}(k)+\frac{1}{2} x_{0}^{\prime 0}(7)\right|=0.62985, \\
\left|s_{1}^{\prime}\right| & =\left|\sum_{k=2}^{6} x_{1}^{\prime 0}(k)+\frac{1}{2} x_{1}^{\prime 0}(7)\right|=0.13605, \\
\left|s_{0}^{\prime}-s_{1}^{\prime}\right| & \\
& =\left|\sum_{k=2}^{6}\left(x_{1}^{\prime 0}(k)-x_{0}^{\prime 0}(k)\right)+\frac{1}{2}\left(x_{1}^{\prime 0}(7)-x_{0}^{\prime 0}(7)\right)\right| \\
& =0.4938 .
\end{aligned}
$$

Therefore, GRID is

$$
\begin{aligned}
r_{01} & =\frac{1+\left|s_{0}^{\prime}\right|+\left|s_{1}^{\prime}\right|}{1+\left|s_{0}^{\prime}\right|+\left|s_{1}^{\prime}\right|+\left|s_{0}^{\prime}-s_{1}^{\prime}\right|} \\
& =\frac{1+0.62985+0.13605}{1+0.62985+0.13605+0.4938} \approx 0.7815 .
\end{aligned}
$$

When $\theta=0.5$ and $\exists \varepsilon_{0}=0.7$, then

$$
\begin{aligned}
\varepsilon_{01} & =\theta \xi_{01}+(1-\theta) r_{01}=0.5 \times 0.7275+0.5 \times 0.7815 \\
& =0.7545>0.7=\varepsilon_{0} .
\end{aligned}
$$

Therefore, according to Table 5, the accuracy was determined to be between grade 2 and grade 3 .

3.3.2. Qualified Verification of the Degree of Grey Incidence on the Amount of Motor Vehicles in Beijing. The original 
TABLE 8: The effects of different APCFs on AMVT, APNG, and ANOG.

\begin{tabular}{|c|c|c|c|c|c|c|c|c|c|}
\hline APCF & AMVT & Trend & $\begin{array}{c}\text { Variation } \\
(\%) \\
\end{array}$ & APMG & Trend & $\begin{array}{c}\text { Variation } \\
(\%) \\
\end{array}$ & ANOG & Trend & $\begin{array}{c}\text { Variation } \\
(\%) \\
\end{array}$ \\
\hline 5 & $3.45229 \mathrm{e}+006$ & -- & -- & 161,737 & -- & -- & 154,899 & -- & -- \\
\hline 10 & $2.87697 \mathrm{e}+006$ & $\downarrow$ & -16.6649 & 139,146 & $\downarrow$ & -13.9677 & 137,782 & $\downarrow$ & -11.0504 \\
\hline 20 & $2.57473 e+006$ & $\downarrow$ & -10.5055 & 126,743 & $\downarrow$ & -8.9137 & 128,122 & $\downarrow$ & -7.0111 \\
\hline 30 & $2.48435 e+006$ & $\downarrow$ & -3.5103 & 123,126 & $\downarrow$ & -2.8538 & 125,306 & $\downarrow$ & -2.1979 \\
\hline 40 & $2.42246 e+006$ & $\downarrow$ & -2.4912 & 120,542 & $\downarrow$ & -2.0987 & 123,272 & $\downarrow$ & -1.6232 \\
\hline 50 & $2.38178 \mathrm{e}+006$ & $\downarrow$ & -1.6793 & 118,839 & $\downarrow$ & -1.4128 & 121,928 & $\downarrow$ & -1.0903 \\
\hline 60 & $2.35237 \mathrm{e}+006$ & $\downarrow$ & -1.2348 & 117,604 & $\downarrow$ & -1.0392 & 120,952 & $\downarrow$ & -0.8005 \\
\hline 70 & $2.32979 e+006$ & $\downarrow$ & -0.9599 & 116,655 & $\downarrow$ & -0.8069 & 120,202 & $\downarrow$ & -0.6201 \\
\hline 80 & $2.31171 \mathrm{e}+006$ & $\downarrow$ & -0.7760 & 115,894 & $\downarrow$ & -0.6524 & 119,599 & $\downarrow$ & -0.5017 \\
\hline 90 & $2.29680 \mathrm{e}+006$ & $\downarrow$ & -0.6450 & 115,265 & $\downarrow$ & -0.5427 & 119,101 & $\downarrow$ & -0.4164 \\
\hline 100 & $2.28421 \mathrm{e}+006$ & $\downarrow$ & -0.5482 & 114,734 & $\downarrow$ & -0.4607 & 118,680 & $\downarrow$ & -0.3535 \\
\hline
\end{tabular}

TABLE 9: Historical data and their simulation values (2009-2015).

\begin{tabular}{lcccc}
\hline \multirow{2}{*}{ Time } & \multicolumn{2}{c}{ Amount of motor vehicles (vehicle) } & \multicolumn{2}{c}{ Amount of population (person) } \\
& Actual value & Simulation value & Actual value & Simulation value \\
\hline 2009 & $4.019 \mathrm{e}+006$ & $4.01900 \mathrm{e}+006$ & $1.8600 \mathrm{e}+007$ & $1.86000 \mathrm{e}+007$ \\
2010 & $4.809 \mathrm{e}+006$ & $4.57571 \mathrm{e}+006$ & $1.9619 \mathrm{e}+007$ & $1.87390 \mathrm{e}+007$ \\
2011 & $4.983 \mathrm{e}+006$ & $5.28216 \mathrm{e}+006$ & $2.0186 \mathrm{e}+007$ & $1.88790 \mathrm{e}+007$ \\
2012 & $5.200 \mathrm{e}+006$ & $5.60956 \mathrm{e}+006$ & $2.0693 \mathrm{e}+007$ & $1.90200 \mathrm{e}+007$ \\
2013 & $5.437 \mathrm{e}+006$ & $5.77509 \mathrm{e}+006$ & $2.1148 \mathrm{e}+007$ & $1.91621 \mathrm{e}+007$ \\
2014 & $5.591 \mathrm{e}+006$ & $5.84424 \mathrm{e}+006$ & $2.1516 \mathrm{e}+007$ & $1.93053 \mathrm{e}+007$ \\
2015 & $5.619 \mathrm{e}+006$ & $5.91422 \mathrm{e}+006$ & $2.1705 \mathrm{e}+007$ & $1.94495 \mathrm{e}+007$ \\
\hline
\end{tabular}

sequence and its simulation value sequence were, respectively, calculated as follows:

$$
\begin{gathered}
X_{i}=\left[\begin{array}{c}
x_{i}(1) \\
x_{i}(2) \\
x_{i}(3) \\
\vdots \\
x_{i}(7)
\end{array}\right]=\left[\begin{array}{c}
4.019 e+006 \\
4.809 e+006 \\
4.983 e+006 \\
5.200 e+006 \\
5.437 e+006 \\
5.591 e+006 \\
5.619 e+006
\end{array}\right], \\
X_{j}=\left[\begin{array}{c}
4.01900 e+006 \\
4.57571 e+006 \\
x_{j}(1) \\
x_{j}(2) \\
x_{j}(3) \\
\vdots \\
5.28216 e+006 \\
x_{j}(7)
\end{array}\right]=\left[\begin{array}{c}
5.60956 e+006 \\
5.84424 e+006 \\
5.91422 e+006
\end{array}\right] .
\end{gathered}
$$

The GAID and GRID were, respectively, calculated as follows:

$$
\begin{aligned}
& \xi_{i j} \approx 0.9235, \\
& r_{i j} \approx 0.9390 .
\end{aligned}
$$

Hence, when $\exists \varepsilon_{0}=0.9$ and $\theta=0.5$,

$$
\varepsilon_{i j}=\theta \xi_{i j}+(1-\theta) r_{i j}=0.9313>0.9=\varepsilon_{0} .
$$

Therefore, according to Definition 3 and Table 5, this model verified the degree of grey incidence and exhibited an accuracy belonging to grade 1 .

\subsection{Policy Simulation Analysis and Discussion}

3.4.1. Horizontal Analysis. According to the horizontal analysis, the curves exhibited different changes with time. The specific analysis results are presented as follows:

Following the adoption of the low charge policy, e.g., $\mathrm{APCF}=5$ yuan/day $\cdot$ vehicle, the AMVT (curve 1) exhibited a decrease since about 2014, as exhibited in Figure 6(a). Although the growth rates of ANOG and APMG exhibited a decrease, the total emissions maintained an increasing trend, thereby resulting in high DAP levels (curve 4). The analysis results indicate the inability of the low charge policy to effectively reduce the DAP.

According to Figure 6(f), curve 1 first exhibited a slow rise (before 2013) and a subsequent sharp descent following the adoption of the high charge policy (APCF $=50$ yuan/day*vehicle). As a result, the AMVT values descended until 2013, wherein its descending range continuously increased. Curve 3 terminated its previously continuous rise and instead descended slowly. Similarly, the rising rate 


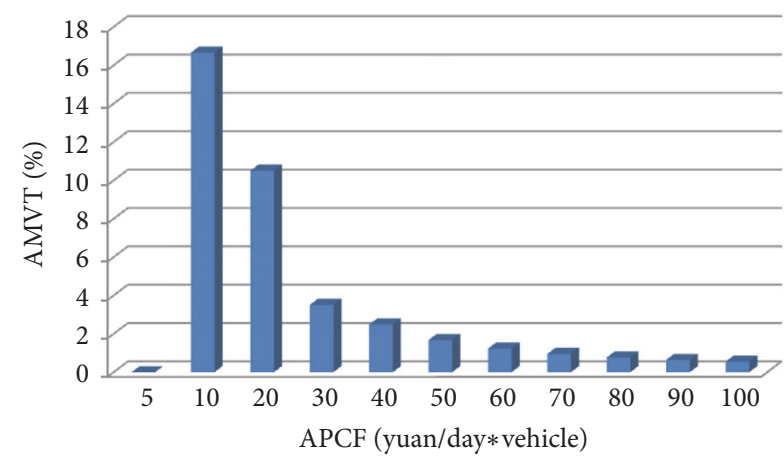

(a) AMVT

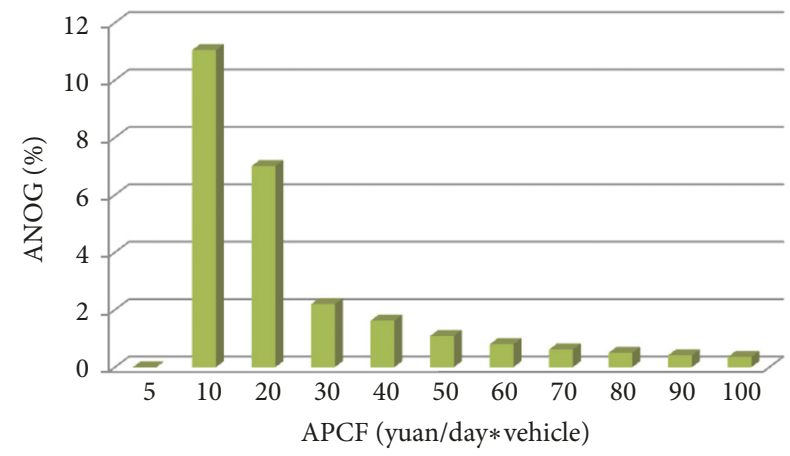

(c) ANOG

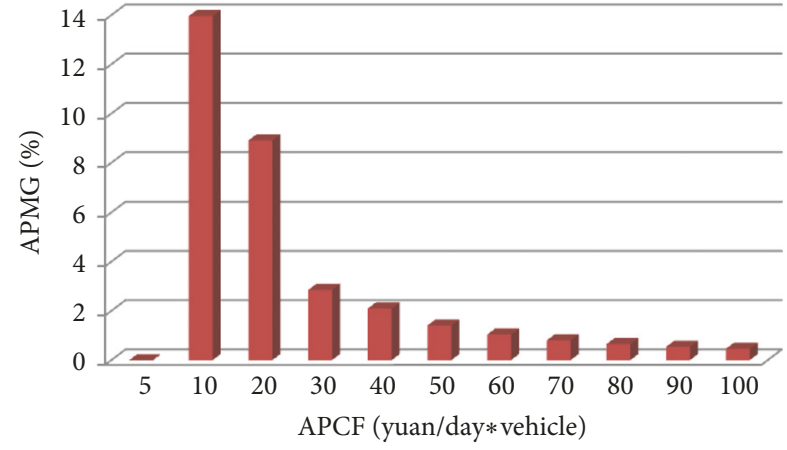

(b) APMG

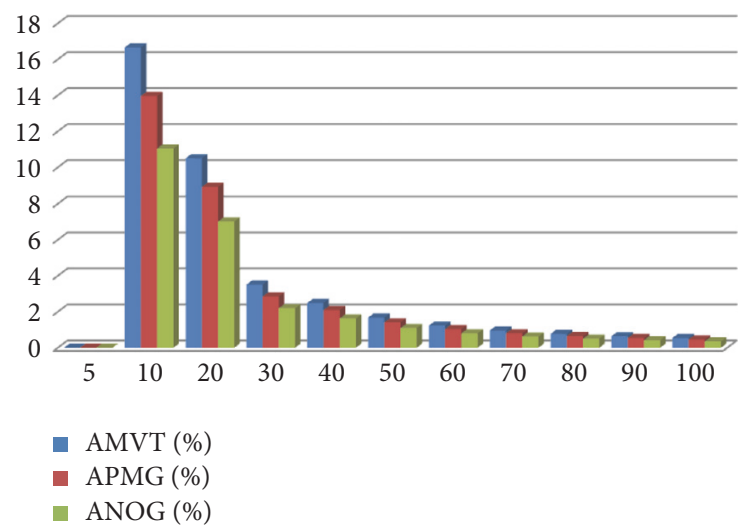

(d) Trend comparison

FIgURE 5: Development trends of the change rates of the main variables. (a) AMVT. (b) APMG. (c) ANOG. (d) Trend comparison.

TABLE 10: The comparison of different policies.

\begin{tabular}{lcccc}
\hline \multirow{2}{*}{ Variable } & \multicolumn{2}{c}{ APCF (yuan/day* vehicle) } & Trend & Variation (\%) \\
\hline AMVT (vehicle) & $\mathbf{5}$ & $\mathbf{5 0}$ & $\downarrow$ & -31.01 \\
APMG (t) & $3.45229 \mathrm{e}+006$ & $2.38178 \mathrm{e}+006$ & $\downarrow$ & -26.52 \\
ANOG (t) & $1.61737 \mathrm{e}+005$ & $1.18839 \mathrm{e}+005$ & $\downarrow$ & -21.29 \\
DAP & $1.54899 \mathrm{e}+005$ & $1.21928 \mathrm{e}+005$ & $\downarrow$ & -12.50 \\
\hline
\end{tabular}

of curve 2 slowed down relatively. These results indicate the effective control on the increase of APMG and ANOG, after which the values began to descend slowly. Curve 4 exhibited three phases, specifically a rapid rise between 2011 and 2014, a slow rise in rate between 2014 and 2018, and a slow descent after 2018. These results indicate the presence of DAP improvements, which exhibited gradual descent after 2018.

The analysis results in Figures 6(b)-6(e) were similar to those presented above.

3.4.2. Vertical Analysis. According to Figures 6(a)-6(f), the APCF exhibited a continuous increase, thereby generating a change in the rules of all the curves as follows:

(i) AMVT (curve 1): The AMVT exhibited a continuous decrease. Within a certain range, the increase in APCF aided in the descent of the AMVT, thereby further alleviating the traffic pressures. (ii) APMG (curve 3) and ANOG (curve 2): A charge of more than 30 (Figures 6(d)-6(f)) generated a slow descent in APMG. Meanwhile, the increase in ANOG also exhibited effective restraint.

(iii) DAP (curve 4): The DAP exhibited an overall decline, especially following the implementation of a high charge policy (APCF $\in[40,50]$ ). A subsequent descending trend was later observed in the period of analogue simulation, as presented in Figures 6(e) and 6(f).

3.4.3. Comparison of Policies. According to Table 10, in the presence of a low charge policy $(\mathrm{APCF}=5)$, the AMVT, APMG, ANOG, and DAP under a high charge policy exhibited an obvious decrease, which indicates that the implementation of a high charge policy effectively reduced motor vehicle exhaust emissions to restrain the 


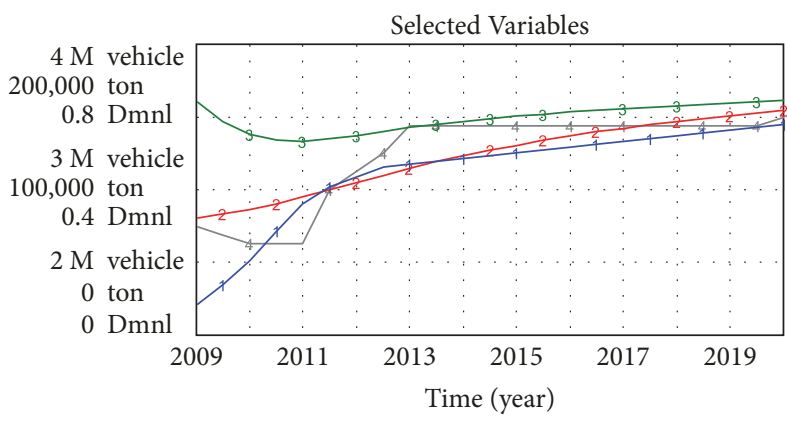

AMVT $:$ APCF $=5 \rightarrow$ vehicle

ANOG : $\mathrm{APCF}=5-2$ ton

$\mathrm{APMG}: \mathrm{APCF}=5 \rightarrow$ ton

$\mathrm{DAP}: \mathrm{APCF}=5-4-\mathrm{Dmnl}$

(a)

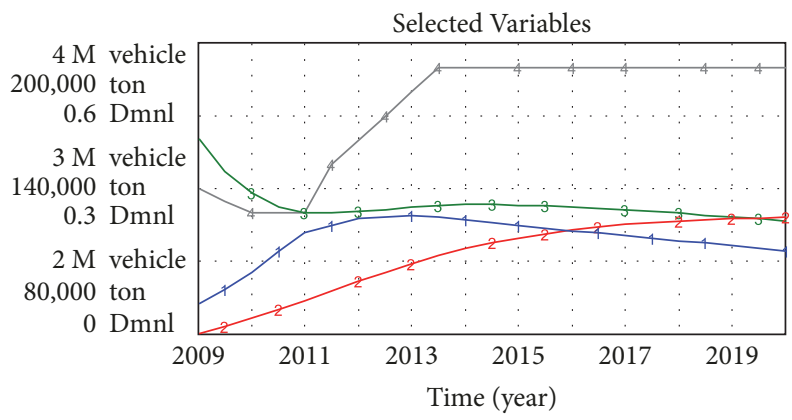

AMVT : $\mathrm{APCF}=20$ - vehicle

ANOG : $\mathrm{APCF}=20 \longrightarrow$ ton

$\mathrm{APMG}: \mathrm{APCF}=20 \rightarrow$ ton

$\mathrm{DAP}: \mathrm{APCF}=20-4-\mathrm{Dmnl}$

(c)

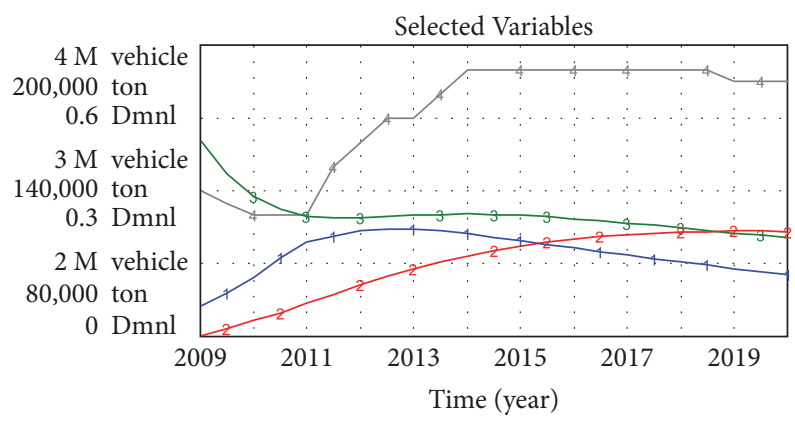

$$
\begin{aligned}
& \text { AMVT }: \text { APCF }=40 \multimap \text { vehicle } \\
& \text { ANOG : } \mathrm{APCF}=40 \multimap \text { ton } \\
& \text { APMG }: \text { APCF }=40 \multimap \text { ton } \\
& \text { DAP : APCF }=40 \longrightarrow \text { Dmnl }
\end{aligned}
$$

(e)

Figure 6: Policy simulation. (a) $\mathrm{APCF}=5$. (b) $\mathrm{APCF}=10$. (c) $\mathrm{APCF}=20$. (d) $\mathrm{APCF}=30$. (e) $\mathrm{APCF}=40$. (f) $\mathrm{APCF}=50$.

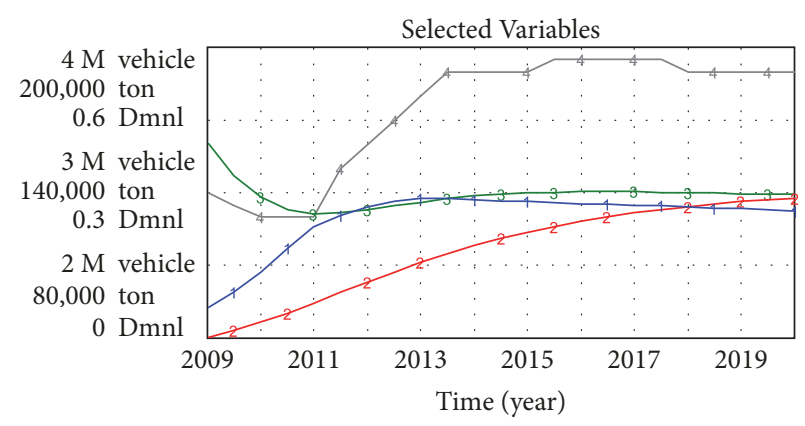

$$
\begin{aligned}
& \text { AMVT : } \mathrm{APCF}=10 \div \text { vehicle } \\
& \text { ANOG : } \mathrm{APCF}=10 \longrightarrow \text { ton } \\
& \text { APMG : } \mathrm{APCF}=10 \smile \text { ton } \\
& \text { DAP : } \mathrm{APCF}=10-4 \text { Dmnl }
\end{aligned}
$$

(b)

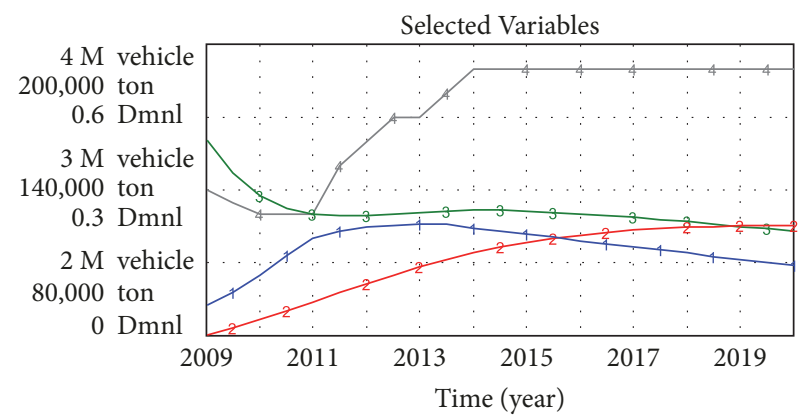

$$
\begin{aligned}
& \text { AMVT }: \text { APCF }=30-\text { vehicle } \\
& \text { ANOG : } \mathrm{APCF}=30-2 \text { ton } \\
& \text { APMG : } \mathrm{APCF}=30-\Im \text { ton } \\
& \text { DAP : APCF }=30 \quad-4-\text { Dmnl }
\end{aligned}
$$

(d)

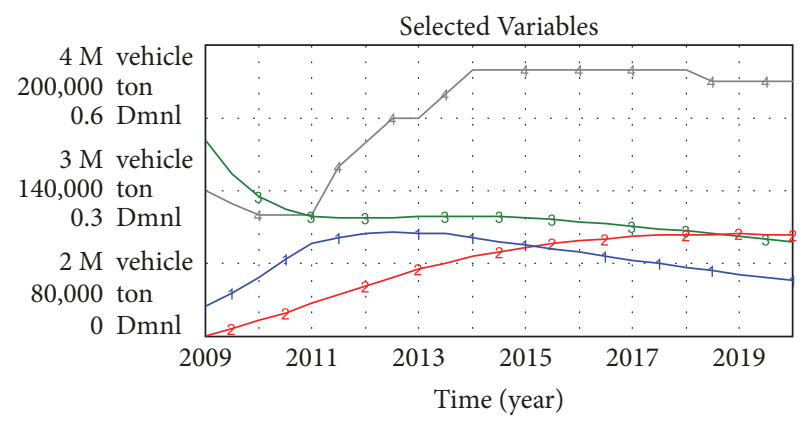

$$
\begin{aligned}
& \text { AMVT }: \text { APCF }=50 \multimap \text { vehicle } \\
& \text { ANOG }: \text { APCF }=50 \multimap \text { ton } \\
& \text { APMG }: \text { APCF }=50 \multimap \text { ton } \\
& \text { DAP : APCF }=50 \multimap-\text { Dmnl }
\end{aligned}
$$

(f) intensification of "haze" pollution degree in Beijing. Specifically, the gap between curves 1 and 2 exhibited a continuous widening, as presented in Figure 7(a). After 2013, curve 2 exhibited an obvious descent. Therefore, the APCF policy effectively reduced the AMVT and enabled an about 31.01\% decrease in 2020.

The results in Figures 7 (b) -7 (d) were similarly analyzed.
In conclusion, the adoption of a low charge policy generated increasing APMG and ANOG trends, as presented in Figures 6(a) and 6(b), thereby suggesting the inability of the low charge policy to effectively reduce the DAP. An increase of the fee to a certain extent, especially following the implementation of a high charge policy (Figures 6(e) and 6(f)), not only reduced the AMVT and alleviated traffic jams 


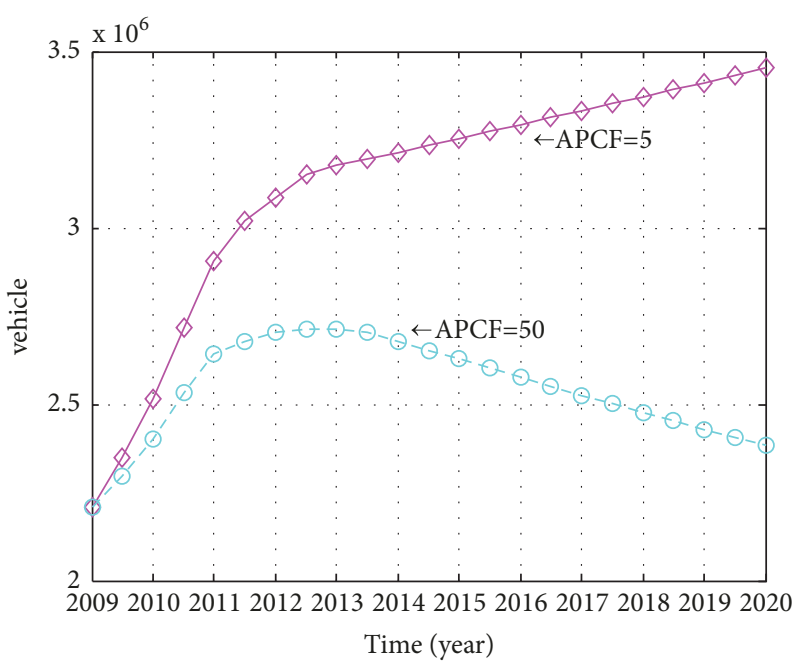

(a) AMVT

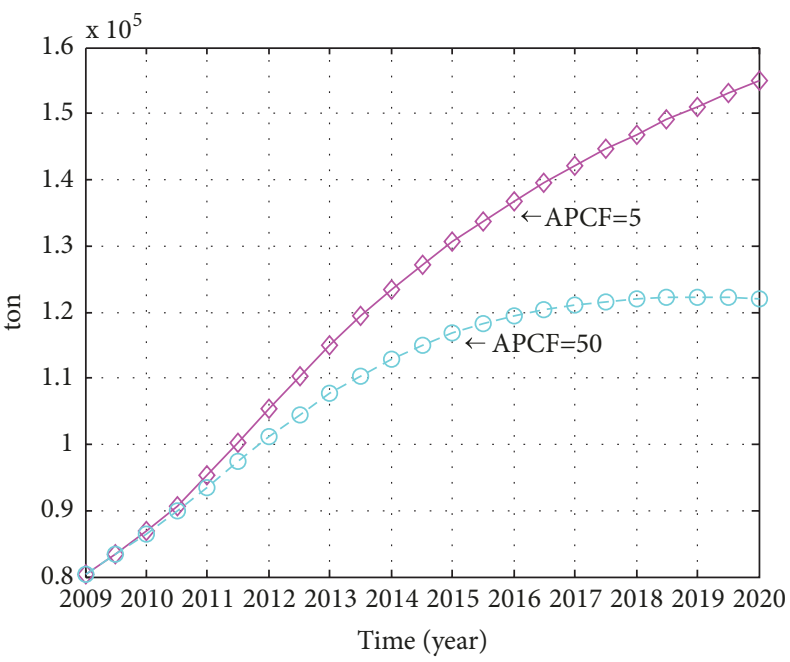

(c) ANOG

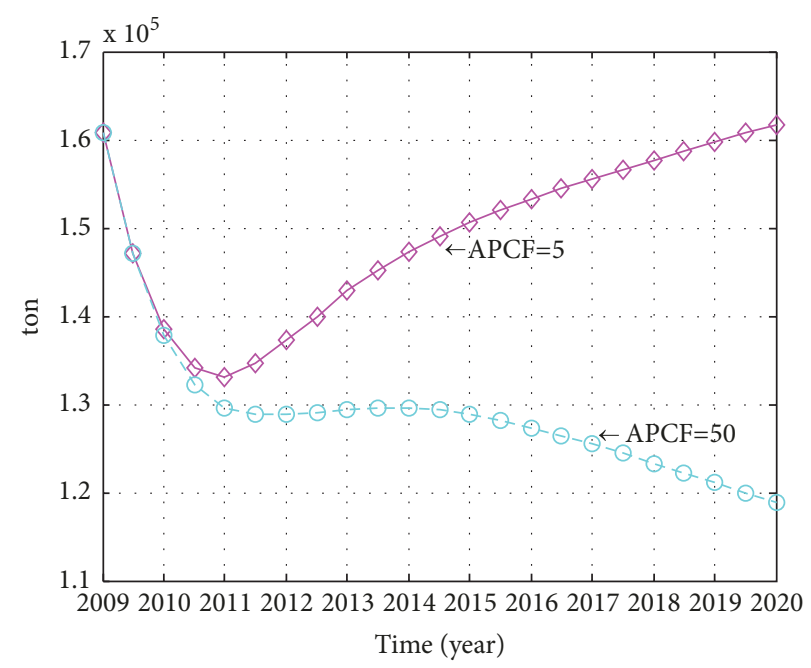

(b) APMG

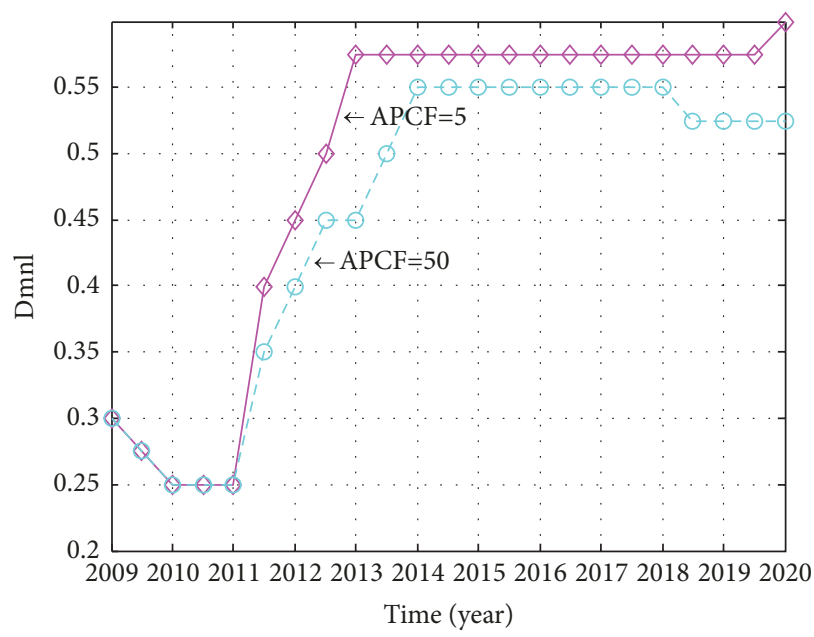

(d) DAP

Figure 7: Comparison of the policies. (a) AVT. (b) APMG. (c) ANOG. (d) DAP.

in cities, but also effectively reduced the APMG and ANOG, thereby reducing the DAP.

According to a comparison on the different schemes, at the end of the analogue simulation period, the high charge policy functioned as follows: in terms of the emission reduction of the motor vehicle exhaust, the APMG and ANOG exhibited reductions of $26.52 \%$ and $21.29 \%$, respectively; in terms of alleviating traffic jams, the AMVT exhibited a 31.01\% decrease; and in terms of reducing the degree of air pollution, the DAP exhibited a $12.50 \%$ decrease.

\section{Conclusions}

4.1. Main Conclusions. To resolve the air pollution problems generated by motor vehicle exhaust emission, the present study introduced the charging mechanism and built a motor vehicle exhaust emission reduction strategy management model using economic means and the SD-GM approach to generate the following conclusions based on tests, validation of the models, and the simulation analysis of policies:

(1) Within a certain range, the reduction effects of APMG and ANOG exhibited continuous enhancements following an increase in APCF. However, the APCF did not always follow the principle "bigger means better" because the emission reduction effect, which was generated by an increase in the APCF, exhibited a marginal decreasing effect. According to the sensitivity analysis, a pollution charge of 30-50 yuan/day.vehicle for the motor vehicles in Beijing was within the relatively reasonable range.

(2) Three high charge policy functions were generated based on a comparison of the simulation results of the different charging schemes: the implementation of high charge policies not only reduced the AMVT and alleviated traffic jams (Figures 6(e), 6(f), and 7(a); Table 10) but also effectively reduced the APMG and ANOG (Figures 6(e), 6(f), $7(\mathrm{~b})$, and 7(c); Tables 5 and 10), thereby further reducing the DAP (Figures 6(e), 6(f), and 7(d); Table 10). According to the 
contrastive analysis, the DAP exhibited a decrease of about $12.50 \%$.

(3) However, the following problems were encountered following the implementation of the APCF policy: (a) The implementation of the APCF policy increased the cost of motor vehicle trips and urged part-time drivers to take public transportation, which increased the burden of public transportation. The subsidy policy and other applicable policies must be introduced to improve the public transport supply level and service quality. Otherwise, the trip demands of passengers will be difficult to satisfy, which will influence the implementation of the APCF policy. (b) In the early periods of APCF policy implementation, an increase in the cost of motor vehicle trips due to the insufficient public understanding and utilization of the APCF policy lowered its public support rate. The government must strengthen its public relations work, especially regarding the purpose and significance of its implementation, to improve public awareness and acknowledgment. (c) The purpose of these policies must be supervised and managed to gather APCF income and improve public transportation infrastructures.

4.2. Deficiencies and Future Work. The present study considered NOx and PMx as the principal motor vehicle emission pollutants. Future research must fully consider other components such as $\mathrm{SO}_{2}$, airborne particles, hydrocarbons, $\mathrm{CO}$, and $\mathrm{CO}_{2}$. Secondly, the implementation of a single charging measure can reduce the supply level of public transportation. Future research should consider a subsidy mechanism to improve the service quality. Thirdly, the function and effect of a single policy are limited. Future work must consider the integration of multiple policies to improve the emission reduction effect. For example, future work may focus priority on public transportation, improvement of fuel quality, vigorous promotion of new energy vehicles, and improvements in emission standards.

\section{Appendix}

A.

See Table 11 .

B.

Summary of the major variables and equations.

(1) Cost of motor vehicle trips = Air pollution charging fee* (1+ Air pollution control)

(2) Amount of NOx generation = INTEG (NOx emissions - Annual dissipation of NOx, 80380)

(3) $\mathrm{NOx}$ emissions $=$ Per vehicle annual of $\mathrm{NOx}$ emissions* Amount of motor vehicle trips* Contribution rate of NOx from vehicle

(4) Contribution rate of NOx from vehicle $=0.5$

(5) Dissipation rate of $\mathrm{NOx}=0.2$

(6) Annual dissipation of $\mathrm{NOx}=$ Amount of $\mathrm{NOx}$ generation $*$ Dissipation rate of $\mathrm{NOx}$

(7) Per vehicle annual of NOx emissions $=0.02$
(8) Amount of PMx generation = INTEG $(\mathrm{PMx}$ emissions- Annual dissipation of PMx, 160760)

(9) PMx emissions = Amount of motor vehicle trips* Contribution rate of PMx from vehicle* Per vehicle annual of PMx emissions

(10) Contribution rate of PMx from vehicle $=0.5$

(11) Per vehicle annual of PMx emissions $=0.04$

(12) Annual dissipation of PMx = Amount of PMx generation $*$ Dissipation and control rate of $\mathrm{PMx}$

(13) Dissipation and control rate of $\mathrm{PMx}=0.5$

(14) Pollution degree of NOx = IF THEN ELSE (Amount of NOx generation $>=1.1182 \mathrm{e}+005,0.9$, IF THEN ELSE (Amount of NOx generation $>=1.0874 \mathrm{e}+005,0.8$, IF THEN ELSE (Amount of NOx generation $>=1.0400 \mathrm{e}+005,0.7$, IF THEN ELSE (Amount of NOx generation $>=9.966 \mathrm{e}+004$, 0.6, IF THEN ELSE (Amount of NOx generation $>=$ $9.618 \mathrm{e}+004,0.5$, IF THEN ELSE (Amount of NOx generation $>=8.038 \mathrm{e}+004,0.3$, IF THEN ELSE (Amount of NOx generation $>=7.008 \mathrm{e}+004,0.25$, IF THEN ELSE (Amount of NOx generation $>=6.144 \mathrm{e}+004,0.2$, IF THEN ELSE (Amount of NOx generation $>=5.508 \mathrm{e}+004,0.15,0.1$ $\left.\left.\left.\left.\left.\int\right)\right)()\right)\right)\right)$ )

(15) Pollution degree of PMx = IF THEN ELSE (Amount of PMx generation $>=2.2364 \mathrm{e}+005,0.9$, IF THEN ELSE (Amount of PMx generation $>=2.1748 \mathrm{e}+005,0.8$, IF THEN ELSE (Amount of PMx generation $>=2.0800 \mathrm{e}+005,0.7$, IF THEN ELSE (Amount of PMx generation $>=1.9932 \mathrm{e}+005$, 0.6, IF THEN ELSE (Amount of PMx generation $>=$ $1.9236 \mathrm{e}+005,0.5$, IF THEN ELSE (Amount of PMx generation $>=1.6076 \mathrm{e}+005,0.3$, IF THEN ELSE (Amount of PMx generation $>=1.4016 \mathrm{e}+005,0.25$, IF THEN ELSE (Amount of PMx generation $>=1.2288 \mathrm{e}+005,0.2$, IF THEN ELSE (Amount of PMx generation $>=1.1016 \mathrm{e}+005,0.15,0.1$ ()$)))()))$

(16) Ratio of motor vehicle trips $=0.55$

(17) Amount of motor vehicle trips = Amount of motor vehicles $*$ Ratio of motor vehicle trips

(18) Degree of air pollution $=$ Weight ratio of $\mathrm{NOx} *$ Pollution degree of $\mathrm{NOx}+$ Weight ratio of $\mathrm{PMx} *$ Pollution degree of PMx

(19) Weight ratio of $\mathrm{PMx}=0.5$

(20) Weight ratio of $\mathrm{NOx}=0.5$

(21) Air pollution control = IF THEN ELSE (Degree of air pollution $>=0.7,1$, IF THEN ELSE (Degree of air pollution $>=$ $0.6,0.8$, IF THEN ELSE (Degree of air pollution $>=0.5,0.7$, IF THEN ELSE (Degree of air pollution $>=0.4,0.6$, IF THEN ELSE (Degree of air pollution $>=0.3,0.5$, IF THEN ELSE (Degree of air pollution $>=0.25,0.45$, IF THEN ELSE (Degree of air pollution $>=0.2,0.4$, IF THEN ELSE (Degree of air pollution $>=0.15,0.35,0.3))))))$ ))

(22) Attraction degree of the growth of vehicles $=(1$-Air pollution control $) * 0.55+$ Attraction degree of vehicle trips $*$ 0.45

(23) Per capita annual income = Amount of GDP/ Amount of population

(24) Amount of population = INTEG (Growth of population+ Net migration- Population reduction, 1.86e+007)

(25) Birth rate $=$ Adjustment coefficient of birth rate* Predictive value of birth rate 
TABLE 11: Description of main variables in stock flow diagram.

\begin{tabular}{|c|c|c|c|}
\hline Significant variable & Unit & Variable type & Data source \\
\hline Air pollution charging fee & yuan/day.vehicle & Constant & \\
\hline Air pollution control & Dmnl & Auxiliary variable & $\mathrm{M}_{1}+\mathrm{M}_{3}$ \\
\hline Amount of GDP & yuan & Level & $\mathrm{M}_{1}$ \\
\hline Amount of motor vehicles & vehicle & Level & $\mathrm{M}_{1}$ \\
\hline Amount of motor vehicle trips & vehicle & Auxiliary variable & \\
\hline Amount of $\mathrm{NOx}(\mathrm{PMx})$ generation & ton & Level & $\mathrm{M}_{1}$ \\
\hline Amount of population & person & Level & $\mathrm{M}_{1}$ \\
\hline Annual dissipation of $\mathrm{NOx}(\mathrm{PMx})$ & ton/year & Flow & \\
\hline Annual scrapped & vehicle/year & Flow & \\
\hline Attraction degree of city & $\%$ & Constant & $\mathrm{M}_{2}$ \\
\hline Attraction degree of the growth of vehicles & $\%$ & Auxiliary variable & $\mathrm{M}_{1}+\mathrm{M}_{3}$ \\
\hline Attraction degree of vehicle trips & $\%$ & Auxiliary variable & $\mathrm{M}_{1}+\mathrm{M}_{3}$ \\
\hline Birth rate & $1 /$ year & Constant & $\mathrm{M}_{3}$ \\
\hline Contribution rate of $\mathrm{NOx}(\mathrm{PMx})$ from vehicle & $\%$ & Constant & $\mathrm{M}_{2}$ \\
\hline Cost of motor vehicle trips & yuan/day·vehicle & Auxiliary variable & $\mathrm{M}_{3}$ \\
\hline Death rate & $1 /$ year & Constant & $\mathrm{M}_{3}$ \\
\hline Degree of air pollution & Dmnl & Auxiliary variable & $\mathrm{M}_{3}$ \\
\hline Dissipation and control rate of $\mathrm{NOx}(\mathrm{PMx})$ & $1 /$ year & Constant & $\mathrm{M}_{2}$ \\
\hline Graphical function of the growth of GDP & Dmnl & Auxiliary variable & $\mathrm{M}_{3}$ \\
\hline Growth of GDP & yuan/year & Flow & \\
\hline Growth rate of motor vehicles & $1 /$ year & Auxiliary variable & $\mathrm{M}_{1}+\mathrm{M}_{3}$ \\
\hline Growth of motor vehicles & vehicle/year & Flow & \\
\hline Growth of population & person/year & Flow & \\
\hline Growth rate of vehicle ownership & Dmnl & Auxiliary variable & $\mathrm{M}_{1}+\mathrm{M}_{3}$ \\
\hline Impact factor of policy & Dmnl & Constant & $\mathrm{M}_{3}$ \\
\hline Net migration & person/year & Flow & \\
\hline Net migration rate & $1 /$ year & Constant & $\mathrm{M}_{1}+\mathrm{M}_{3}$ \\
\hline NOx (PMx) emissions & ton/year & Flow & \\
\hline Per capita annual income & yuan/person & Auxiliary variable & \\
\hline Per vehicle annual of NOx (PMx) emissions & ton/year·vehicle & Constant & $\mathrm{M}_{2}$ \\
\hline Pollution degree of NOx (PMx) & Dmnl & Auxiliary variable & $\mathrm{M}_{1}+\mathrm{M}_{3}$ \\
\hline Population reduction & person/year & Flow & \\
\hline Ratio of motor vehicle trips & $\%$ & Constant & $\mathrm{M}_{2}$ \\
\hline Scrap rate & $1 /$ year & Constant & $\mathrm{M}_{2}$ \\
\hline The average of net migration rate & $1 /$ year & Constant & $\mathrm{M}_{1}$ \\
\hline Weight ratio of PMx (NOx) & $\%$ & Auxiliary variable & $\mathrm{M}_{3}$ \\
\hline
\end{tabular}

(26) Predictive value of birth rate $=0.00925$

(27) Death rate $=$ Adjustment coefficient of death rate $*$ Predictive value of death rate

(28) Predictive value of death rate $=0.00494$

(29) Net migration $=$ Amount of population $*$ Net migration rate

(30) Net migration rate $=$ The average of net migration rate $*$ Attraction degree of city $^{\wedge}$ (Impact factor of policy)

(31) Impact factor of policy $=1.5$

(32) The average of net migration rate $=0.00531$

(33) Attraction degree of city $=0.7056$

(34) Amount of GDP = INTEG (Growth of GDP, $1.2153 \mathrm{e}+012)$
(35) Graphical function of the growth of GDP $=$ WITH LOOKUP (Amount of GDP, ([(8e+011, 0)- $(3 \mathrm{e}+012,0.3)]$, $(8.1178 \mathrm{e}+011,0.1648), \quad(9.8468 \mathrm{e}+011,0.213), \quad(1.1115 \mathrm{e}+012$, $0.1288), \quad(1.2153 \mathrm{e}+012, \quad 0.0934), \quad(1.41136 \mathrm{e}+012, \quad 0.1613)$, $(1.62519 \mathrm{e}+012,0.1515),(1.78794 \mathrm{e}+012,0.1001),(1.98008 \mathrm{e}+012$, $0.1075), \quad(2.13308 \mathrm{e}+012,0.0773), \quad(2.30146 \mathrm{e}+012,0.0789)$, $(2.35396 \mathrm{e}+012,0.02281),(2.40162 \mathrm{e}+012,0.0203),(2.45025 \mathrm{e}+$ $012,0.02025), \quad(2.49987 \mathrm{e}+012,0.02024),(2.55049 \mathrm{e}+012$, $0.020249))$ )

(36) Growth rate of GDP = Graphical function of the growth of GDP* Impact factor of the growth of GDP

(37) Amount of motor vehicles = INTEG (Growth of motor vehicles- Annual scrapped, 4.019e+006) 
(38) Annual scrapped $=$ Amount of motor vehicles* Scrap rate

(39) Scrap rate $=0.067$.

\section{Conflicts of Interest}

The author declares no conflicts of interest.

\section{Acknowledgments}

This work has been partially supported by the National Natural Science Foundation of China (71571119), Shanghai First-Class Academic Discipline Project (S1201YLXK), and China Postdoctoral Science Foundation (2018M630404). The author would like to thank LetPub (http://www.letpub.com/) for providing linguistic assistance during the preparation of this manuscript.

\section{References}

[1] X. Liu, S. Ma, J. Tian, N. Jia, and G. Li, "A system dynamics approach to scenario analysis for urban passenger transport energy consumption and $\mathrm{CO}_{2}$ emissions: A case study of Beijing," Energy Policy, vol. 85, pp. 253-270, 2015.

[2] B. Xu, L. Luo, and B. Lin, "A dynamic analysis of air pollution emissions in China: Evidence from nonparametric additive regression models," Ecological Indicators, vol. 63, pp. 346-358, 2016.

[3] S. Leinert, H. Daly, B. Hyde, and B. Ó. Gallachóir, "Co-benefits? Not always: Quantifying the negative effect of a $\mathrm{CO}_{2}$-reducing car taxation policy on NOx emissions," Energy Policy, vol. 63, pp. 1151-1159, 2013.

[4] Z. Cheng, L. Li, and J. Liu, "Identifying the spatial effects and driving factors of urban $\mathrm{PM}_{2.5}$ pollution in China," Ecological Indicators, vol. 82, pp. 61-75, 2017.

[5] N. Kaida and K. Kaida, "Spillover effect of congestion charging on pro-environmental behavior," Environment, Development and Sustainability, vol. 17, no. 3, pp. 409-421, 2015.

[6] R. Peñabaena-Niebles, V. Cantillo, and J. L. Moura, "Impact of transition between signal timing plans in social cost based in delay, fuel consumption and air emissions," Transportation Research Part D: Transport and Environment, vol. 41, pp. 445456, 2015.

[7] D. Ding and B. Shuai, "A traffic restriction scheme for enhancing carpooling," Discrete Dynamics in Nature and Society, Article ID 9626938, 9 pages, 2017.

[8] D. Kong, X. Guo, B. Yang, and D. Wu, "Analyzing the Impact of Trucks on Traffic Flow Based on an Improved Cellular Automaton Model," Discrete Dynamics in Nature and Society, vol. 2016, pp. 1-14, 2016.

[9] S. Cakmak, C. Hebbern, J. D. Cakmak, and J. Vanos, “The modifying effect of socioeconomic status on the relationship between traffic, air pollution and respiratory health in elementary schoolchildren," Journal of Environmental Management, vol. 177, pp. 1-8, 2016.

[10] L. Song, H. Song, J. Lin et al., " $\mathrm{PM}_{2.5}$ emissions from different types of heavy-duty truck: a case study and meta-analysis of the Beijing-Tianjin-Hebei region," Environmental Science and Pollution Research, vol. 24, no. 12, pp. 11206-11214, 2017.
[11] Z. Hu, S. Kang, C. Li et al., "Light absorption of biomass burning and vehicle emission-sourced carbonaceous aerosols of the Tibetan Plateau," Environmental Science and Pollution Research, vol. 24, no. 18, pp. 15369-15378, 2017.

[12] X. Cen, H. K. Lo, and L. Li, "A framework for estimating traffic emissions: The development of Passenger Car Emission Unit," Transportation Research Part D: Transport and Environment, vol. 44, pp. 78-92, 2016.

[13] S. Wang, X. Liu, C. Zhou, J. Hu, and J. Ou, "Examining the impacts of socioeconomic factors, urban form, and transportation networks on CO2 emissions in China's megacities," Applied Energy, vol. 185, pp. 189-200, 2017.

[14] Q. Wang, K. Hubacek, K. Feng, Y.-M. Wei, and Q.-M. Liang, "Distributional effects of carbon taxation," Applied Energy, vol. 184, pp. 1123-1131, 2016.

[15] C. Johansson, L. Burman, and B. Forsberg, "The effects of congestions tax on air quality and health," Atmospheric Environment, vol. 43, no. 31, pp. 4843-4854, 2009.

[16] A. Rakowska, K. C. Wong, T. Townsend et al., "Impact of traffic volume and composition on the air quality and pedestrian exposure in urban street canyon," Atmospheric Environment, vol. 98, pp. 260-270, 2014.

[17] S. Batterman, R. Ganguly, and P. Harbin, "High resolution spatial and temporal mapping of traffic-related air pollutants," International Journal of Environmental Research and Public Health, vol. 12, no. 4, pp. 3646-3666, 2015.

[18] J. Eliasson, M. Börjesson, D. van Amelsfort, K. Brundell-Freij, and L. Engelson, "Accuracy of congestion pricing forecasts," Transportation Research Part A: Policy and Practice, vol. 52, pp. 34-46, 2013.

[19] J. Eliasson, "The role of attitude structures, direct experience and reframing for the success of congestion pricing," Transportation Research Part A: Policy and Practice, vol. 67, pp. 81-95, 2014.

[20] H. X. Yang, J. D. Li, H. Zhang, and S. Q. Liu, "Research on the governance of urban traffic jam based on system dynamics," Systems Engineering Theory and Practice, vol. 34, no. 8, pp. 21352143, 2014 (Chinese).

[21] M. H. Zhu, Research on Socio-Economic Impact of Urban Traffic Congestion [PhD thesis], Beijing Jiaotong University, 2013 (Chinese).

[22] B. Zeng, Research on Modeling Technologies of Grey Prediction [PhD thesis], Nanjing University of Aeronautics and Astronautics, 2011 (Chinese).

[23] S. F. Liu, Y. J. Yang, and L. F. Wu, Grey System Theory and Application, Science Press, Beijing, China, 2017.

[24] S. W. Jia, K. Yang, J. J. Zhao, and G. L. Yan, "The trafficcongestion charging fee management model based on the system dynamics approach," Mathematical Problems in Engineering, vol. 2017, Article ID 3024898, 13 pages, 2017. 


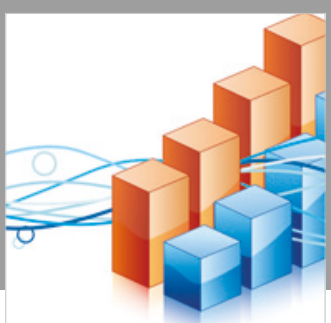

Advances in

Operations Research

\section{-n-m}
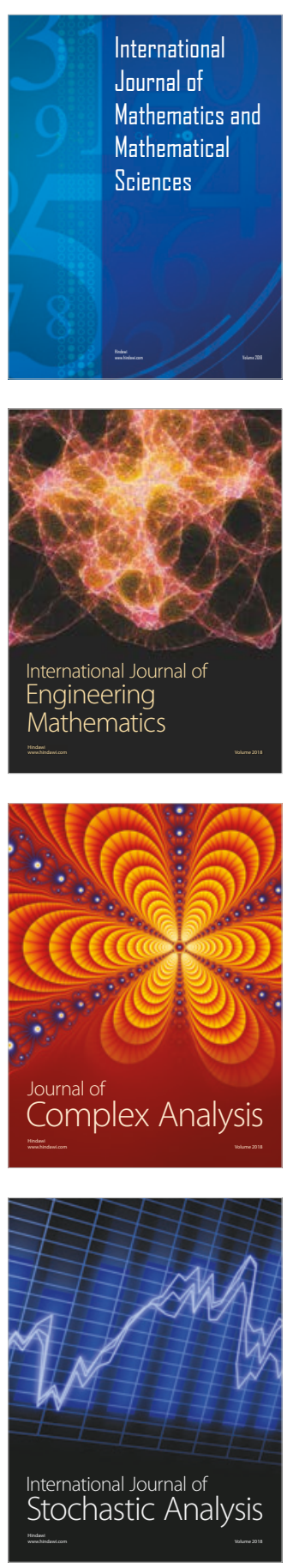
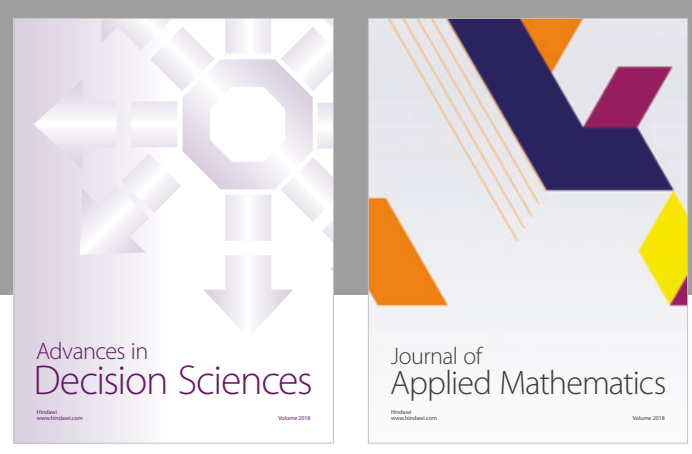

Journal of

Applied Mathematics
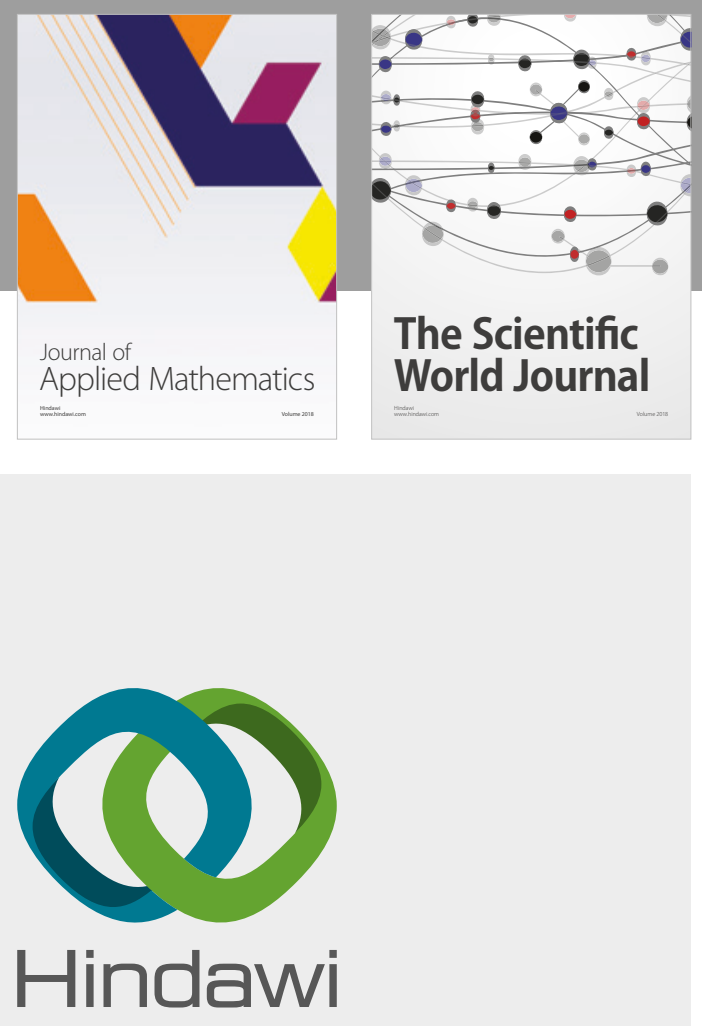

Submit your manuscripts at

www.hindawi.com

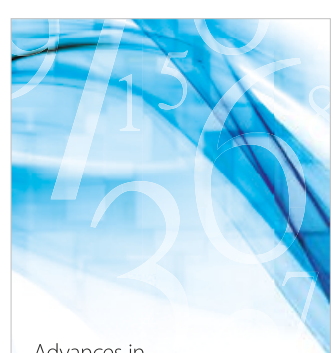

Advances in
Numerical Analysis
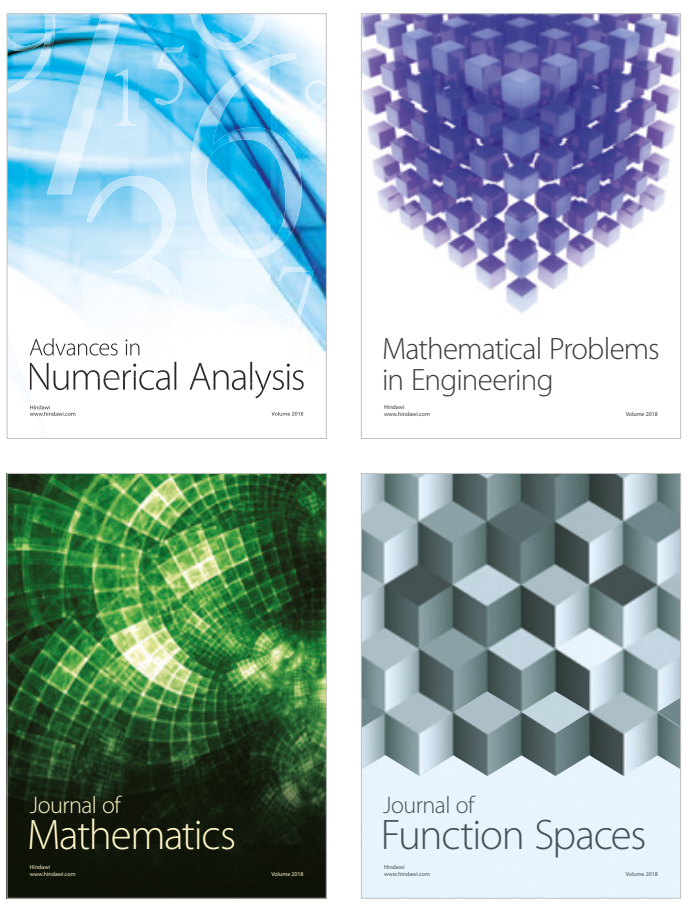

Mathematical Problems in Engineering

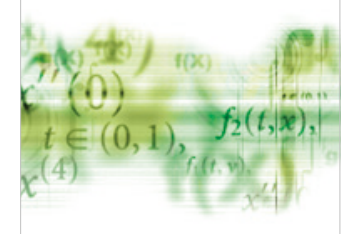

International Journal of

Differential Equations

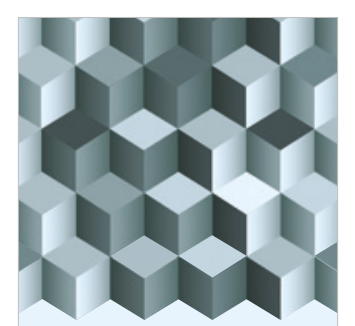

Journal of

Function Spaces

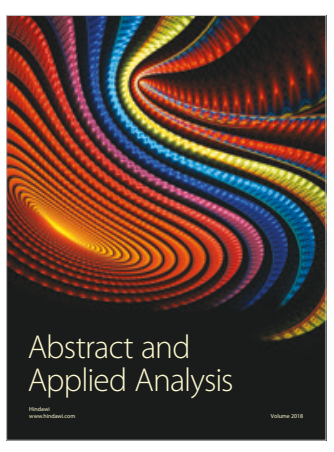

The Scientific

World Journal

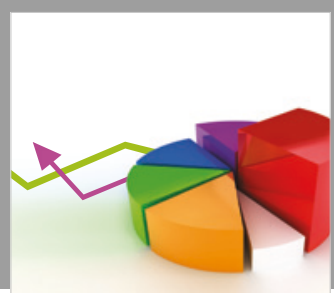

Journal of

Probability and Statistics
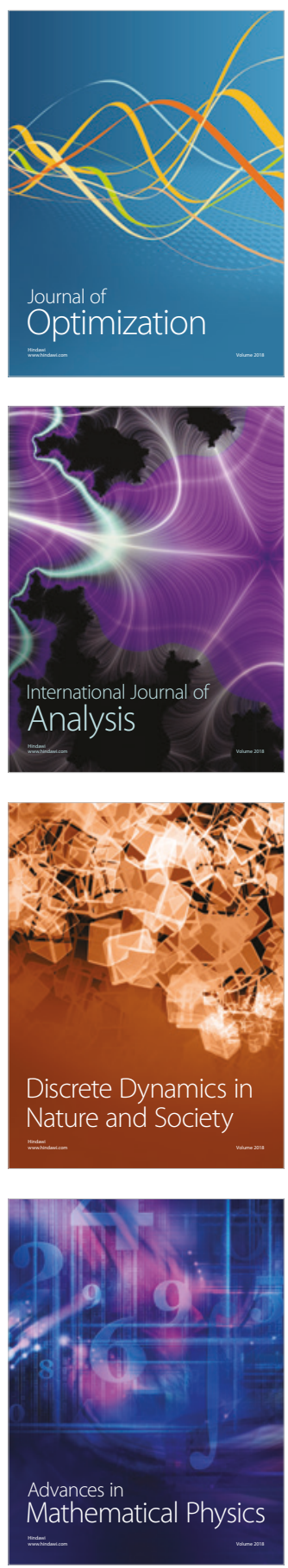